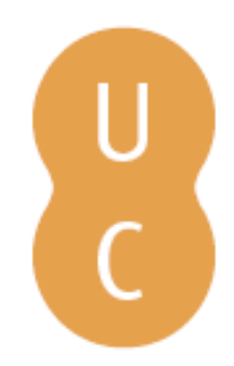

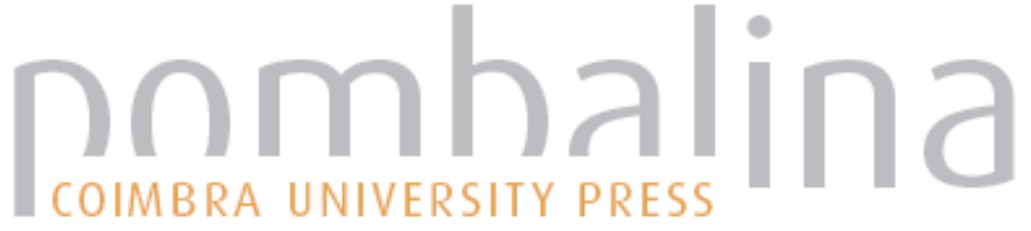

\section{O factor tempo nas condições de trabalho: o caso do trabalho por turnos}

\author{
Autor(es): $\quad$ Silva, Isabel Soares da \\ Publicado por: Imprensa da Universidade de Coimbra \\ URL \\ persistente: \\ URI:http://hdl.handle.net/10316.2/31236 \\ DOI: \\ DOI:http://dx.doi.org/10.14195/978-989-26-0238-7_8 \\ Accessed : $\quad$ 26-Apr-2023 16:07:46
}

A navegação consulta e descarregamento dos títulos inseridos nas Bibliotecas Digitais UC Digitalis, UC Pombalina e UC Impactum, pressupõem a aceitação plena e sem reservas dos Termos e Condições de Uso destas Bibliotecas Digitais, disponíveis em https://digitalis.uc.pt/pt-pt/termos.

Conforme exposto nos referidos Termos e Condições de Uso, o descarregamento de títulos de acesso restrito requer uma licença válida de autorização devendo o utilizador aceder ao(s) documento(s) a partir de um endereço de IP da instituição detentora da supramencionada licença.

Ao utilizador é apenas permitido o descarregamento para uso pessoal, pelo que o emprego do(s) título(s) descarregado(s) para outro fim, designadamente comercial, carece de autorização do respetivo autor ou editor da obra.

Na medida em que todas as obras da UC Digitalis se encontram protegidas pelo Código do Direito de Autor e Direitos Conexos e demais legislação aplicável, toda a cópia, parcial ou total, deste documento, nos casos em que é legalmente admitida, deverá conter ou fazer-se acompanhar por este aviso.

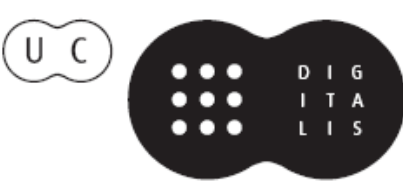



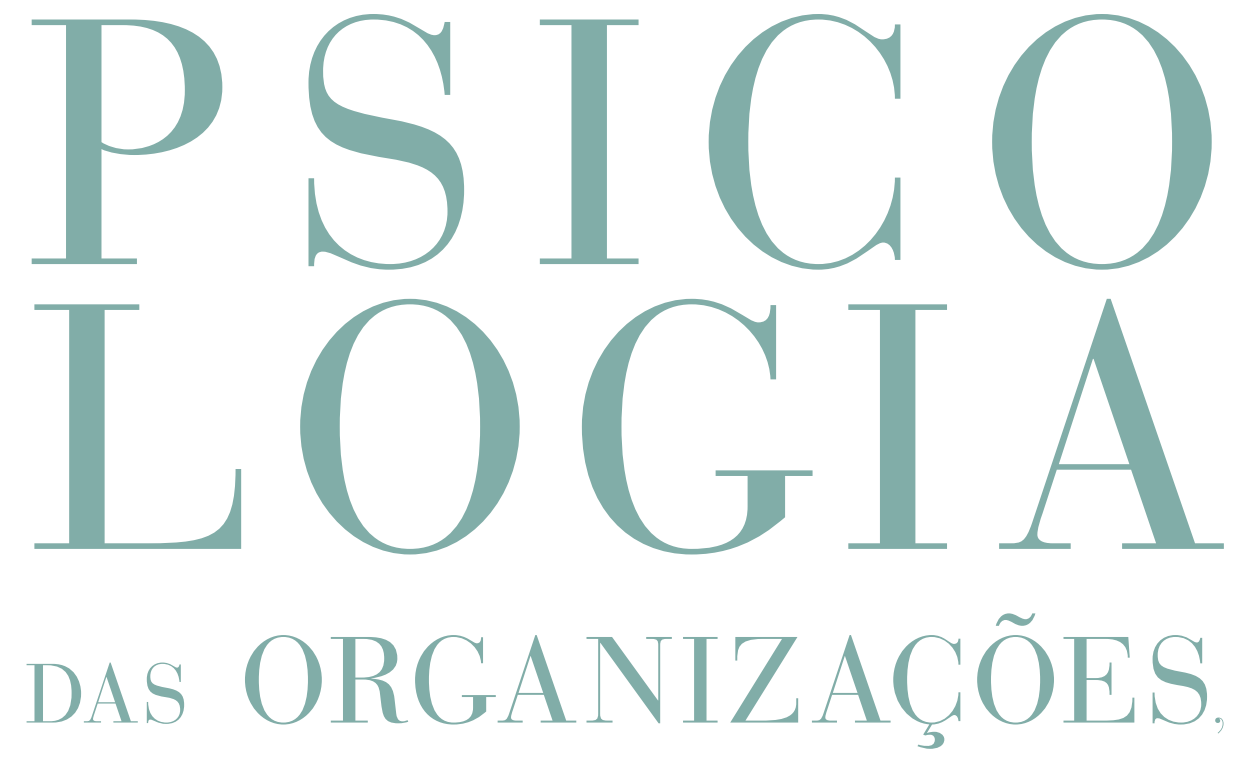

DO TRABALHO E DOS RECURSOS HUMANOS

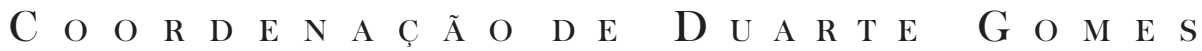

\section{Coimpra Companions}




\section{VIII}

O FACTOR TEMPO NAS CONDIÇÕES DE TRABALHO: O CASO DO TRABALHO

POR TURNOS

Isabel Soares da Silva

UNIVERSIDADE DO MINHO 
(Página deixada propositadamente em branco) 


\section{INTRODUÇ̃̃O ${ }^{1}$}

Society provides the framework according to which time is arranged and crucial elements of this framework in modern western society are work and clock.

Blyton, Hassard, Hill e Starkey, 1992, p. 2.

Shiftwork has long been recognized as an occupational health and safety hazard.

Di Milia, Bohle, Loundon e Pisarski, 2008, p. 539.

O tempo de trabalho constitui um dos elementos chave das condições laborais, uma dimensão que se liga ao coração da relação de emprego e que tem impacto para além do trabalho (Parent-Thirion, Macías, Hurley \& Vermeylen, 2007). Com efeito, os horários de trabalho não estruturam somente 
quando é que a actividade laboral é realizada, mas estruturam, igualmente, o tempo disponível para as restantes esferas da vida dos indivíduos, como as esferas familiar, social ou de lazer (tipicamente, o "tempo livre" é encarado como o tempo fora do trabalho). Por outro lado, a organização temporal da sociedade estrutura-se em grande medida à volta dos horários de trabalho. O planeamento da programação televisiva ou a organização das actividades recreativas em massa são exemplos de situações que reflectem a interdependência entre esses dois domínios. Como sublinha Boulin (1993), o modo como o tempo é gasto fora do trabalho é constrangido pela organização decorrente do sistema de tempo de trabalho, sendo esta organização caracterizada por um elevado grau de sincronização entre as diferentes actividades sociais e económicas. De facto, a maioria dos serviços (ex., educação, serviços públicos) encontram-se coordenados com as restantes actividades económicas, enquanto que os serviços orientados para o lazer seguem um regime temporal igualmente articulado com os horários de trabalho da maioria da população, encontrando-se disponíveis durante os períodos normalmente reservados ao repouso, nomeadamente, ao final do dia, fins-de-semana e períodos de férias.

Os horários de trabalho podem variar na sua duração, na sua alocação no período das vinte e quatro horas, na regularidade dessa alocação ou no grau de controlo que é dado ao trabalhador sobre essa variação. Nesse sentido, como sublinha Fagan (2001a), o número de horas que um trabalho exige, a parte do dia e da semana no qual ele é realizado e o grau de controlo que é dado ao trabalhador sobre essa variação têm uma influência determinante no conjunto e na ordenação do tempo para actividades domésticas e sociais. Tais dimensões constituem a estrutura dos horários de trabalho, permitindo, em conjunto, moldar a fronteira entre o emprego e o "tempo pessoal".

Assim, os aspectos temporais do trabalho representam um factor não tangível, mas com um elevado potencial de estruturação, dentro e fora do contexto de trabalho (Gracia, Peiró \& Ramos, 2002), assumindo um carácter determinante na estruturação dos tempos societal e individual (Blyton et al., 1992; Boulin, 1993; Fagan, 2001a). Contrariamente às comunidades agrícolas, onde a passagem das estações e o ciclo dia-noite governavam o ritmo de 
vida diária, a industrialização envolveu a crescente regulação, por parte dos empregadores, do tempo dos trabalhadores (Hewitt, 1993). Como sublinha a autora, com a industrialização, chegam os contratos regulados mais pelas horas trabalhadas do que pelas tarefas realizadas, ou, como refere Boulin (1993), a organização social do tempo que predomina nas sociedades desenvolvidas tem sido moldada pela disciplina do tempo introduzida pela revolução industrial e seus desenvolvimentos subsequentes.

Até meados do século xx, a organização dos horários de trabalho pode caracterizar-se, segundo Thierry e Jansen (1998), por uma dicotomia - trabalho diurno e trabalho irregular ou trabalho por turnos - sendo que a maioria dos trabalhadores nos países industrializados trabalhavam apenas durante o dia (manhã e tarde), folgando ao fim de semana. No entanto, ainda que a maioria dos trabalhadores estivesse afecta a essa modalidade horária, dando, por conseguinte, a ideia de que se trata do horário "normal" ou "natural", os autores sublinham que a história da organização do tempo de trabalho nos países ocidentais evidencia que todo o tipo de variações tem existido ao longo dos séculos e que a duração dos horários de trabalho, tanto em dias de semana trabalhados como em horas diárias, foi durante muito tempo superior às típicas oito horas diárias, cinco dias por semana.

Nas últimas décadas, porém, tem-se assistido à tendência crescente para a implementação de horários de trabalho alternativos ao horário considerado normal ou convencional (i.e., caracterizado pela duração de 7 a 8 horas por dia, de segunda a sexta-feira e realizado durante o dia) em variados sectores de actividade (Beers, 2000; Boisard, Cartron, Gollac \& Valeyre, 2003; Parent-Thirion et al., 2007). Por exemplo, segundo o Terceiro Inquérito às Condições de Trabalho levado a cabo em 2000 pela Fundação Europeia para a Melhoria das Condições de Vida e do Trabalho, mais de um terço da população activa da União Europeia (15 Estados Membros) tinha um horário de trabalho diferente do horário "normal" das oito horas diárias e mais de um quinto trabalhava por turnos, embora mais de metade (54\%) realizasse um horário de trabalho semanal com duração compreendida entre as 36 e as 40 horas (Boisard et al., 2003). De acordo com a mesma fonte, 18\% dessa população trabalhava pelo menos uma noite por mês, 47\% trabalhava pelo menos um sábado por mês e $24 \%$ trabalhava pelo menos um domingo por 
mês. Dados mais recentes derivados do Quarto Inquérito às Condições de Trabalho, realizado em 2005 sob os auspícios da mesma entidade (embora com base em 27 Estados), suportam, sob algum aspecto, a adopção de modalidades horárias alternativas à convencional. Com efeito, 50\% dos trabalhadores inquiridos não trabalha o mesmo número de horas por dia, cerca de 40\% não tem horários fixos de início e de fim do seu trabalho e cerca de 30\% não trabalha o mesmo número de dias por semana (Parent-Thirion et al., 2007).

Ao que tudo indica, a tendência para a diversificação dos horários de trabalho é para continuar graças à combinação de três tipos de factores: económicos, tecnológicos e sócio-culturais. Por exemplo, no contexto das mudanças económicas e tecnológicas, factores como a globalização da economia, a proliferação da tecnologia de informação e a exigência crescente para a disponibilidade de bens e de serviços por parte dos consumidores, entre outros, têm contribuído nos últimos anos e, nas palavras de Smith, Folkard e Fuller (2003: 163), para a criação de uma "sociedade de vinte e quatro horas". Também a crescente concorrência entre mercados, a preocupação pela maximização do equipamento produtivo, em especial nas indústrias de capital intensivo, a par de um melhor ajustamento da capacidade produtiva às flutuações dos mercados são argumentos frequentemente utilizados para justificar a necessidade de reorganização do tempo de trabalho (Boulin, 1993; Knauth, 1998; Allan, Brosman \& Walsh, 1998; Schabracq \& Cooper, 2000), quer em direcção ao aumento do tempo de laboração das organizações quer em direcção a uma maior flexibilização temporal no uso da força de trabalho por parte destas. Quanto às mudanças sócio-culturais, os próprios desenvolvimentos que abraçam diversos aspectos da evolução das sociedades, tais como desenvolvimentos demográficos, mudanças no mercado de trabalho e transformação nos estilos de vida e nas aspirações das pessoas acentuarão, provavelmente, a tendência em direcção à redução e à reorganização do tempo de trabalho (Boulin, 1993; Hewitt, 1993; Allan et al., 1998). Por exemplo, a análise de preferências do tempo de trabalho por parte dos trabalhadores tem indicado que as soluções mais preferidas em termos de duração semanal do horário de trabalho correspondem a um horário "substancial" a tempo parcial (20 a 34 horas) ou a um horário 
"moderado" a tempo inteiro (entre 35 a 39 horas) (Fagan, Warren e McAllister, 2001; Fagan, 2002). A análise de tais preferências também tem indicado o desejo de um maior controlo por parte dos trabalhadores sobre o seu tempo de trabalho (Fagan, 2001b).

Entre as diversas modalidades horárias existentes, consta a organização do horário de trabalho por turnos, a qual, tem sido tipicamente definida como o "modo de organização diária do horário de trabalho no qual diferentes equipas trabalham em sucessão de modo a estenderem os horários de trabalho, incluindo o prolongamento até às 24 horas diárias" (Costa, 1997: 89). É sobre esta modalidade horária que o presente capítulo versa primariamente, revendo as principais consequências a si associadas bem como os principais processos/mecanismos subjacentes à sua génese. No entanto, antes de avançarmos para esses tópicos, fazemos no ponto seguinte uma referência aos elementos que permitem caracterizar os diversos horários de trabalho e descrevemos sumariamente dois horários alternativos ao horário de trabalho convencional, nomeadamente, o horário de trabalho flexível (flexitime) e a semana de trabalho reduzida (compressed workweek). A opção por esta breve descrição deve-se ao facto de ser frequente encontrar combinações de certos aspectos que caracterizam tais sistemas com determinadas configurações que os horários de trabalho por turnos podem exibir (ex., semana de trabalho reduzida através da implementação de turnos de 12 horas). Concluímos esse ponto com uma apresentação das principais características que os sistemas de turnos podem assumir.

\section{HorÁRIOS DE TRABALHO}

Embora existam diferenças assinaláveis entre os diferentes tipos de horários de trabalho, é possível identificar um conjunto de dimensões que permitem estruturar qualquer tipo de horário de trabalho. Nesse contexto, Gracia e colaboradores (2002: 134), enumeram nove dimensões, nomeadamente: i) número de horas de trabalho diário; ii) número de horas de trabalho semanal; iii) distribuição diária das horas de trabalho (alocação do período de trabalho durante o dia); iv) dias semanais de trabalho e de 
descanso; v) dias de trabalho consecutivos; vi) dias de descanso consecutivos; vii) distribuição dos dias de descanso ao longo da semana; viii) jornada de trabalho diária contínua versus descontínua (i.e., se a jornada de trabalho é interrompida ou não); ix) grau de flexibilidade (discricionariedade na escolha de diversos aspectos relativos ao horário de trabalho, como, por exemplo, horários de entrada e saída ou número de horas a realizar durante uma determinada semana). As primeiras oito dimensões podem ter carácter fixo ou variável, tendo os autores designado este aspecto como grau de variabilidade. A partilha de certas dimensões entre os múltiplos sistemas de horários de trabalho que são passíveis de se obter a partir da combinação de todas as dimensões referidas permite distinguir os diferentes tipos de sistemas horários entre si.

\subsection{HORÁRIO DE TRABALHO FLEXÍVEL}

Um horário de trabalho é considerado flexível quando os trabalhadores gozam de certa capacidade de escolha em relação a determinados aspectos do seu horário de trabalho, tipicamente o horário de início e de término (Tepas, 1985; Thierry \& Jansen, 1998; Baltes, Briggs, Huff, Wright \& Neuman, 1999), podendo essa capacidade ser alargada também à escolha do horário para almoço (Thierry \& Jansen, 1998). O período de tempo dentro do horário total de trabalho em que todos os trabalhadores devem estar na organização é designado como tempo nuclear ou horas nucleares (Golembiewski \& Proehl, 1978; Thierry \& Jansen, 1998; Baltes et al., 1999).

Para além da alocação e da duração das horas de trabalho nucleares no seio do período de trabalho diário, Golembiewski e Proehl (1978) apontam mais seis dimensões através das quais os sistemas de horários flexíveis podem diferir: i) amplitude da banda (leque horário compreendido entre a primeira e a última hora de trabalho permitida por um determinado sistema horário); ii) horas flexíveis (número total de horas que o trabalhador pode escolher em cada dia de trabalho); iii) duração da semana de trabalbo (número máximo de horas que o trabalhador pode trabalhar numa determinada semana); iv) sistema de créditos/débitos 
(banking) (possibilidade do trabalhador poder adiantar ou ficar a "dever" horas num determinado período de referência); v) liberdade de variação do sistema pelo trabalhador (grau pelo qual o trabalhador pode ou não variar horas de trabalho de dia para dia ou de semana para semana sem aprovação prévia); vi) papel do supervisor (inclui aspectos relacionados com o modo como o supervisor controla e/ou negoceia as horas com os trabalhadores e a possibilidade daquele alterar o sistema, quando as necessidades organizacionais assim o exijam). A combinação destas dimensões ou a ausência de alguns dos seus aspectos resulta numa grande variedade de arranjos horários. Por outro lado, refira-se também que a escolha do início e do fim do trabalho pode não ser feita a título individual, mas por grupos de trabalhadores, nomeadamente, quando o trabalho a realizar implica interdependência desses grupos (Thierry \& Jansen, 1998). Na revisão efectuada por Baltes e colaboradores (1999), esta modalidade horária encontrava-se quase que exclusivamente implementada em organizações não industriais.

Os ganhos individuais e organizacionais que se presume resultarem da implementação deste sistema horário são diversificados. A nível individual é enfatizada a expectativa de uma melhor conciliação entre a vida profissional e a vida pessoal oferecida pela maior autonomia dada ao trabalhador (incluindo maior facilidade na deslocação casa-trabalho), enquanto que a nível organizacional são referidos impactos positivos em termos de produtividade, absentismo, turnover e satisfação profissional (Tepas, 1985; Raltson, 1989). A este propósito, a literatura tem salientado a escassez de estudos focados na avaliação da implementação deste tipo de horário, especialmente aqueles com um design considerado adequado, como, por exemplo, a inclusão de grupos de controlo/experimental ou com carácter longitudinal (Golembiewski \& Proehl, 1978; Raltson, Anthony \& Gustafson, 1985; Thierry \& Jansen, 1998; Baltes et al., 1999). Por outro lado, os estudos nem sempre têm suportado os ganhos hipotetizados, em especial a nível organizacional (produtividade e absentismo) (Thierry \& Jansen, 1998). O facto de os sistemas poderem assumir grandes variações torna muito difícil a tarefa de se pronunciarem afirmações taxativas sobre as vantagens e as desvantagens associadas à modalidade horária (Tepas, 1985). 
No sentido de ultrapassar as deficiências descritas anteriormente, Baltes e colaboradores (1999) realizaram uma meta-análise com vista a estimar o efeito de duas modalidades horárias (horários de trabalho flexíveis e semana de trabalho reduzida) em quatro critérios relacionados com o trabalho: i) produtividade e desempenho (auto-avaliado e avaliado pelo supervisor); ii) absentismo; iii) satisfação no trabalho; iv) satisfação com o sistema horário. Na estimativa dos efeitos foram também consideradas as seguintes variáveis moderadoras: i) tipo de ocupação (exercício de funções de gestão ou não); ii) grau de flexibilidade permitido pelo sistema (inferior ou igual a cinco horas ou superior a cinco horas); iii) tempo decorrido desde a implementação do sistema (inferior ou igual a seis meses ou superior a seis meses); iv) rigor metodológico dos estudos (reduzido ou elevado). À excepção do desempenho (auto-avaliado), os restantes critérios relacionados com o trabalho (produtividade, absentismo, satisfação laboral e satisfação com o sistema horário) foram favoravelmente influenciados pelo sistema horário flexível, tendo sido o absentismo o mais afectado e a satisfação laboral a menos afectada. Ao nível das variáveis moderadoras, os resultados obtidos foram os seguintes: i) tipo de ocupação (o sistema horário apenas afectou positivamente os trabalhadores sem funções de gestão); ii) grau de flexibilidade do sistema (contrariamente ao hipotetizado, foi observado um maior efeito nos sistemas com menor grau de flexibilidade, isto é, com cinco ou menos horas flexíveis); iii) tempo desde a implementação (os efeitos tendem a diminuir à medida que o tempo avança); iv) rigor metodológico (esta dimensão apenas afectou o tamanho dos efeitos observados, sendo que os estudos com maior rigor metodológico exibiram efeitos de tamanho maiores quando comparados com estudos de baixo rigor).

Dos resultados obtidos por Baltes e colaboradores (1999), salientamos o relativo ao facto de um elevado grau de flexibilidade (nesta análise operacionalizado como mais de cinco horas flexíveis) poder conduzir à diminuição dos efeitos positivos. Segundo os autores, um sistema com muitas horas flexíveis pode exigir ao trabalhador um maior esforço na monitorização do seu horário de trabalho (o qual poderá atenuar os efeitos positivos sentidos) ou pode colocar problemas ao nível da comunicação e/ou finalização das tarefas (quando a sua realização exige interdependência). Thierry e Jansen 
(1998), levantam também a questão de um sistema horário flexível poder ser menos "seguro" quando inclui a possibilidade de horas creditadas/ debitadas, dado que este mecanismo poderá favorecer horários de trabalho muito longos no decurso do período das vinte e quatros horas.

Para além dos eventuais constrangimentos mencionados anteriormente, têm sido associados outros custos decorrentes da implementação desta modalidade horária, dos quais salientamos a necessidade de um maior planeamento e controle por parte da organização e o aumento de custos resultantes do alargamento do período de laboração (ex., Golembiewski \& Proehl, 1978; Tepas, 1985). De qualquer maneira, como concluem Baltes e colaboradores (1999) com base na sua meta-análise, os dados disponíveis apontam para o facto dos horários de trabalho flexíveis terem efeitos primariamente positivos nas variáveis relacionadas com o contexto de trabalho, os quais deverão compensar eventuais custos exigidos aos empregadores decorrentes da sua implementação.

\subsection{SEMANA DE TRABALHO REDUZIDA}

A semana de trabalho reduzida caracteriza-se pela redução do número de dias trabalhados na semana, com o consequente aumento da duração do horário de trabalho diário dado que a duração do horário semanal se mantém (Thierry \& Jansen, 1998; Baltes et al., 1999). As configurações horárias adoptadas podem variar no número de dias da semana trabalhados e respectivas durações de trabalho diário (ex., se se considerar uma semana de trabalho de quarenta horas, o sistema pode ser composto por quatro dias de trabalho por semana, tendo cada dia a duração de dez horas). Para além do número de dias de semana trabalhados e da duração de trabalho dos mesmos, os sistemas podem diferir na variabilidade dos dias de trabalho e de não trabalho (i.e., grau em que o número de dias de trabalho e de descanso consecutivos se mantém ou não) (Tepas, 1985), embora, tipicamente, os sistemas contemplem uma semana de trabalho fixa ou regular (Gracia et al., 2002). A implementação deste sistema pode resultar na redução ou na extensão do tempo de trabalho médio semanal numa dada organização, 
embora a situação mais típica seja a de permitir o aumento do tempo operacional. Este aumento é obtido habitualmente através da aplicação combinada com outros regimes horários como o trabalho por turnos, ou, menos frequentemente, com o trabalho a tempo parcial (Thierry \& Jansen, 1998).

Para além da rentabilização dos meios de produção e do alargamento do período de prestação de serviços, têm sido associados outros benefícios a esta modalidade horária quer para as organizações quer para os indivíduos a ela submetidos (ver, por exemplo, a lista de potenciais vantagens e desvantagens referida por Tepas, 1985). Os estudos empíricos centrados na avaliação desta modalidade horária, globalmente, não têm permitido chegar a conclusões claras, especialmente em relação a algumas das variáveis consideradas. Por exemplo, a revisão realizada por Thierry e Jansen (1998) de vários estudos empíricos, levaram os autores a concluir que os resultados ao nível do absentismo e do turnover não são claros. Ao nível da produtividade, embora haja também resultados mistos, regista-se, no entanto, uma tendência de melhoria, sobretudo no período que se segue à implementação do sistema. Quanto às atitudes dos trabalhadores submetidos a este sistema, praticamente todos os estudos revistos apontaram para uma avaliação favorável, especialmente por parte dos mais jovens.

Os resultados obtidos na meta-análise de Baltes e colaboradores (1999), a que já fizemos referência, globalmente, são consistentes com as conclusões anteriores. De facto, a introdução deste sistema horário influenciou positivamente o desempenho (avaliado pelo supervisor), a satisfação com o sistema horário, a satisfação no trabalho (tendo este sido o critério mais afectado), mas não a produtividade e o absentismo. Quanto às duas variáveis moderadoras consideradas - tempo decorrido após a implementação do sistema horário e rigor metodológico - não foram detectadas diferenças significativas.

Do ponto de vista individual, a principal vantagem associada a este sistema horário resulta do maior bloco de tempo livre proporcionado pela redução da semana de trabalho. A principal desvantagem apontada à modalidade representa, no entanto, o reverso da vantagem mencionada. Ou seja, o facto dos dias de trabalho serem mais longos conduz, por um lado, à redução do tempo livre nos dias de trabalho e, por outro, pode conduzir 
a elevados níveis de fadiga comprometedores quer da "qualidade" do tempo livre nesses dias quer do desempenho profissional. A revisão de Thierry e Jansen (1998) de vários estudos que procuraram avaliar o impacto da modalidade ao nível da fadiga não permitiu, no entanto, obter conclusões claras a esse respeito. Como salientam os autores, a fadiga pode resultar não apenas da submissão do trabalhador ao horário de trabalho, mas também da interacção com outros factores de natureza extra-ocupacional (ex., obrigações domésticas e familiares).

\subsection{HORÁRIO DE TRABALHO POR TURNOS}

No geral, os autores (ex., Tepas, 1985; Brunstein \& Andlauer, 1988; Thierry \& Jansen, 1998; Åkerstedt, 1990; Gracia et al., 2002; Smith et al., 2003) têm adoptado a definição de horário de trabalho por turnos similar à apresentada por Costa (1997), onde a questão da sucessão das equipas de trabalho com vista à extensão do período de laboração de uma dada organização constutui o aspecto central.

No entanto, o conceito de trabalho por turnos tem sido também aplicado na literatura a outros tipos de horários de trabalho, como horários menos estruturados e irregulares, horários nocturnos, horários compreendidos entre a tarde e a noite (Åkerstedt, 1990), ou ainda, a qualquer horário que divirja do horário considerado normal (Monk \& Folkard, 1992; Knutsson, 2004). Ainda que a investigação sobre esta problemática privilegie sistemas que envolvem algum modo de trabalho nocturno, Monk e Folkard (1992) advogam uma concepção mais lata do conceito, nomeadamente a sua aplicação a qualquer horário efectuado regularmente fora da janela temporal que define o horário de trabalho considerado normal por entenderem que tal operacionalização contempla o impacto da interferência deste regime nas esferas familiar e social.

Os sistemas de turnos podem variar largamente em diversos aspectos. Um dos aspectos diz respeito à alternância ou não das equipas pelos diferentes turnos. Assim, os sistemas de turnos são classificados como permanentes ou fixos quando os trabalhadores se encontram afectos sempre 
ao mesmo turno (ex., trabalham sempre no turno das 23 h às 7 h) ou são rotativos quando os trabalhadores têm de alternar periodicamente entre diferentes turnos (ex., alternar a cada dois dias entre o turno da manhã, da tarde e da noite) (Costa, 1997).

Em termos da combinação do número de dias da semana trabalhados e do envolvimento ou não de trabalho nocturno, os sistemas de turnos podem ser classificados como: descontínuos (interrupção do trabalho no período nocturno e ao fim de semana); semi-contínuos (24 horas de trabalho nos dias úteis, ou seja, interrupção do trabalho ao fim de semana); contínuos (todos os dias da semana são trabalhados, 24 horas por dia, 365 dias por ano) (Brunstein \& Andlauer, 1988; Thierry \& Jansen, 1998; Totterdell, 2005). É sobretudo ao nível dos sistemas contínuos que se encontram as estruturas horárias mais variadas, sendo esta complexidade devida à intervenção de um certo número de parâmetros como, por exemplo, o número de equipas (exigindo pelo menos três equipas em laboração e uma em repouso), a frequência de mudança de turnos ou o número e a alocação dos dias de repouso. Por outro lado, esta configuração constitui a forma mais intensiva de trabalho por turnos (Wedderburn, 1998). Com efeito, esta envolve inevitavelmente, por um lado, trabalho nocturno (o horário que previsivelmente mais dificuldades coloca do ponto de vista da adaptação biológica) e, por outro, trabalho ao fim de semana (período considerado pela maioria dos trabalhadores como o mais perturbador do ponto de vista da vida familiar e social). A laboração contínua pode, no entanto, ser também conseguida através do acoplamento de "equipas suplementares" (que laboram apenas durante o fim de semana, tipicamente em turnos de 12 horas) a um sistema semi-contínuo (Brunstein \& Andlauer, 1988).

Nos sistemas rotativos pode-se ainda caracterizar a velocidade e o sentido de rotação. A velocidade de rotação define-se pelo tempo ("dias") que um trabalhador permanece num dado turno antes de mudar para o turno seguinte (Folkard, Minors \& Waterhouse, 1985), podendo os sistemas, globalmente, ser classificados como de rotação rápida ou lenta. De um modo geral, a literatura (ex., Folkard et al., 1985; Kanuth, 1996) considera rotação rápida quando o trabalhador está num dado turno até três dias consecutivos antes de alternar para outro. Em todo o caso, ressalve-se que 
esta tipologia, mesmo na literatura mais recente, não é unânime. Por exemplo, Pilcher, Lambert e Huffcutt (2000) definiram no âmbito da sua meta-análise sistemas de rotação rápida como aqueles em que o tempo de permanência num dado turno fosse inferior ou igual a quatro dias e sistemas de rotação lenta quando esse tempo fosse superior a quatro dias.

O sentido de rotação refere-se à direcção em que a alternância entre os turnos é efectuada, podendo esta fazer-se no sentido dos ponteiros do relógio (i.e., turno da manhã - turno da tarde - turno da noite) ou em direcção contrária a esse sentido (i.e., turno da noite - turno da tarde - turno da manhã). Quando o movimento de alternância segue o sentido dos ponteiros, diz-se que a rotação é em atraso de fase e quando o movimento de alternância é contrário a esse sentido designa-se sistema em avanço de fase (Barton \& Folkard, 1993). Além das configurações apresentadas, podem existir sistemas mais complexos, resultantes da sua combinação, sendo, nesse caso, designados como sistemas híbridos.

Para além das características anteriores, os sistemas de turnos podem igualmente diferir noutros aspectos como os horários de início e de término dos turnos, o número e a alocação temporal dos dias de folga ou a regularidade/irregularidade dos ciclos de trabalho (um ciclo de trabalho compreende o período entre um "bloco" de trabalho e o "bloco" de folga que se lhe segue até dar início a outro de período de trabalho). Os sistemas de turnos podem igualmente incorporar outros elementos caracterizadores de outras modalidades horárias como, por exemplo, a redução dos dias de semana trabalhados, característica da semana de trabalho reduzida, ou a possibilidade de variação de certos aspectos pelos trabalhadores, característica dos horários flexíveis. Por exemplo, entre os casos reais que Kogi (1985) apresenta como possibilidades de arranjos horários flexíveis, um deles diz respeito a uma empresa suíça que alargou o horário de trabalho flexível a um sistema de dois turnos. Especificamente, no período de sobreposição entre o turno da manhã e o turno da tarde (o turno da manhã iniciava-se às 5 horas e o da tarde terminava as 20 horas) existia a possibilidade de escolha (parcial) por parte dos trabalhadores, nomeadamente no horário de término e no horário de início dos respectivos turnos. 
Embora existam registos de que certas funções (ex., transporte, segurança, padeiros, parteiras) têm sido realizadas ao longo dos tempos durante o período nocturno, de modo regular ou pontual (Mott, Mann, McLoughlin \& Warwich, 1965; Scherrer, 1981; Tepas, 1985), o trabalho por turnos característico da era moderna teve a sua origem no final do século XVIII e início do século Xix (Kogi, 1985), tendo a introdução da luz artificial em grande escala sido uma das mudanças que facilitou a extensão do período de laboração (Scherrer, 1981). Neste período, como refere Kogi (1985), a laboração diária de muitas indústrias era extensa, tendo sido rapidamente introduzidas equipas de trabalhadores de modo a assegurar essa laboração. Com efeito, a prevalência do trabalho por turnos tal como conhecemos actualmente é um produto da industrialização (Mott et al., 1965), tendo aumentado de modo gradual nos países industrializados no período pós segunda Guerra Mundial (Blyton, 1992). Além do aumento da capacidade produtiva, outros factores de natureza económica, entre os quais se destacam a amortização acelerada dos elevados capitais investidos em equipamentos, a par de uma cada vez mais rápida obsolescência dos mesmos, têm impelido as organizações a fazer uma utilização completa do tempo operacional (Brunstein \& Andlauer 1988; Blyton et al., 1992).

Não obstante as razões económicas, há certos sectores de actividade que por imperativos de natureza técnica têm necessidade de introduzir a laboração contínua, como é o exemplo das indústrias química, metalúrgica ou refinarias dada a inviabilidade de parar determinados processos de laboração e/ou dos elevados custos decorrentes do seu encerramento (Mott et al., 1965; Kogi, 1985; Brunstein \& Andlauer 1988; Blyton et al., 1992; Wedderburn, 1998). Por outro lado, os avanços tecnológicos em determinadas áreas, como a informática, a par de maiores exigências por parte dos consumidores, têm conduzido à extensão do horário de trabalho, incluindo a laboração contínua, em sectores de prestação de serviços privados que tradicionalmente operavam apenas no horário de laboração dito convencional (Wedderburn, 1998). É precisamente o alargamento a este tipo de sectores que tem contribuído recentemente para a manutenção ou a expansão do número de pessoas submetidas a este tipo de horário de trabalho, envolvendo, por conseguinte, populações novas com características sócio-profissionais variadas, para além das tradicionais indústrias 
transformadoras. Em todo o caso, refira-se que a prevalência de trabalho por turnos continua a ser maior no contexto industrial face ao sector dos serviços. Por exemplo, os dados reportados por Boisard e colaboradores (2003) indicam que o trabalho por turnos envolve principalmente os trabalhadores da indústria e os trabalhadores dos sectores de serviços e comercial, respectivamente, $42.7 \%$ e $28.2 \%$. Por fim, há factores de ordem social que têm impelido e continuarão a impelir a adopção desta modalidade horária em determinadas organizações prestadoras de serviços, nomeadamente de bens públicos. Com efeito, serviços como a segurança pública (ex., polícia, bombeiros), cuidados de saúde ou a prestação de bens públicos (ex., electricidade, gás ou água), é esperado que o seu funcionamento seja assegurado de modo ininterrupto ao longo de 24 horas por dia, 365 dias por ano.

Em jeito de conclusão, podemos dizer que embora o trabalho por turnos seja um fenómeno que tem atravessado as sociedades ao longo dos tempos, um dos aspectos que o distingue desde a era industrial diz respeito ao número crescente de trabalhadores envolvidos, alargamento que, nas últimas décadas, se está a fazer sobretudo a partir da sua penetração noutros sectores de actividade, especialmente na área dos serviços. Por outro lado, referimos também que os sistemas de turnos que mais exigências colocam do ponto de vista da adaptação são aqueles que envolvem a realização de trabalho nocturno - de modo permanente ou alternado - e/ou que exigem trabalhar em períodos socialmente valorizados, donde se destaca o período de fim-de-semana. No ponto que se segue, procuraremos detalhar tais consequências.

\section{CONSEQUÊNCIAS DO TRABALHO POR TURNOS}

De um modo geral, as consequências associadas ao trabalho por turnos podem ser agrupadas nos seguintes domínios: biológico (perturbações dos ritmos circadianos e do sono), médico (perturbações na saúde física e psicológica), social (perturbações nas esferas familiar e social) (Folkard et al., 1985; Costa, 1996; Smith et al., 2003) e laboral (perturbações circadianas do desempenho e sua relação com a segurança ocupacional) (Costa, 1996). 
Este ponto encontra-se estruturado de acordo com esta tipologia. Embora o estabelecimento de categorias facilite a tarefa de sistematização da informação disponível, como veremos ao longo da sua descrição, estas tendem a estar de algum modo entrelaçadas. Por exemplo, as perturbações no ciclo sono-vigília, ainda que integradas num domínio mais biológico podem ter repercussões do ponto de vista laboral (ex., segurança), noutras facetas da saúde e/ou da vida familiar e social. Por outro lado, as dificuldades derivadas da interferência do regime horário com as esferas familiar e social podem desencadear e/ou exacerbar as dificuldades com o sono.

\subsection{PERTURbaÇÃo dos Ritmos CiRCADiANOS E DO SONO}

\subsubsection{RITMOS CIRCADIANOS ${ }^{2}$}

Não obstante os diversos relatos ao longo da história, foi apenas a partir do início do século vinte que as evidências em termos da demonstração das estruturas internas responsáveis pela ritmicidade e do seu modo de funcionamento se multiplicaram (Menna-Barreto \& Marques, 2000). Com efeito, diversos estudos e procedimentos experimentais, como o protocolo de rotinas constantes, experiências com tempo alterado ou experiências de isolamento temporal (Minors \& Waterhouse, 1981; Duffy \& Dijk, 2002) permitiram, por um lado, determinar a natureza endógena dos ritmos circadianos e, por outro, estudar a interacção entre as componentes endógena e exógena da ritmicidade observada. Tomemos a título de exemplo as experiências de isolamento temporal com humanos. Estas experiências são realizadas em condições onde se procura controlar todos os factores susceptíveis de proporcionar informação temporal aos sujeitos (ex., níveis de luminosidade,

\footnotetext{
Os ritmos circadianos referem-se a ritmos cujo período é de cerca de um dia (do latim, circa dies), compreendido entre as 20 e as 28 horas. O prefixo circa salienta o facto do período intrínseco do sistema temporal que controla os ritmos endógenos em muitas espécies, incluindo a humana, não corresponder exactamente às 24 horas do dia solar (Minors \& Waterhouse, 1981).
} 
som, temperatura), podendo ser levadas a cabo em grutas de elevada profundidade ou em unidades laboratoriais construídas especificamente para o efeito (Minors \& Waterhouse, 1981). Os resultados deste tipo de estudos têm indicado que os ritmos circadianos persistem, embora, com períodos ligeiramente diferentes das 24 horas (Wever, 1985). O facto de a ritmicidade persistir ao longo do tempo nestas circunstâncias, aponta pois, para a existência de um sistema temporal endógeno, auto-sustentado (Minors \& Waterhouse, 1981; Moore-Ede \& Sulzman, 1992; Moore, 1997; Duffy \& Dijk, 2002), metaforicamente designado de "relógio biológico" (Minors \& Waterhouse, 1985). No caso do ser humano, uma série de ritmos espontâneos com periodicidade circadiana foram já identificados, de que são exemplo, a temperatura corporal, sono-vígilia, cortisol, mitoses celulares, potássio urinário, humor, esforço percebido, força muscular ou velocidade de reacção visual (Minors \& Waterhouse, 1985; Silva et al., 1996; Armstrong, 2000).

Através das experiências de isolamento temporal é possível também determinar o período endógeno circadiano humano, tendo as observações realizadas revelado que este é ligeiramente superior ao período observado em condições normais (neste caso, de 24 horas) (Minors \& Waterhouse, 1981, 1985; Wever, 1985; Aschoff \& Wever, 1992). O prolongamento do período dos ritmos não foi, no entanto, a única mudança observada em estudos desta natureza. Com efeito, foi também observado que os ritmos circadianos tendem a estabelecer entre si novas relações de fase ao longo do tempo (Wever, 1985; Aschoff \& Wever, 1992). Por exemplo, nas experiências realizadas por Aschoff e Wever até meados da década de 70 e descritas por Lavie (2001), envolvendo 150 indivíduos, para além do prolongamento do período endógeno, foi também observado o estabelecimento de novas relações de fase entre os ritmos circadianos da temperatura central e do sono-vigília, relações que se mantiveram nalguns indivíduos, até ao final do período experimental. Nalguns sujeitos, no entanto, a sincronização interna entre os ritmos da temperatura e do sono-vigília sob as novas relações de fase, duraram apenas alguns dias (Wever, 1985; Lavie, 2001), observando-se um fenómeno que tem sido designado como dessincronização interna ou dessincronose (Minors \& Waterhouse, 1981; 
Aschoff \& Wever, 1992; Moore-Ede \& Sulzman, 1992; Silva et al., 1996), o qual, se caracteriza pela perda das relações de fase habituais entre os ritmos. Ou seja, após certa exposição a um ambiente onde há privação de pistas temporais externas (designado como ambiente de livre curso) é observada, em alguns indivíduos, uma dissociação dos ritmos entre si, podendo estes "correr" espontaneamente com períodos distintos (Wever, 1985). Este fenómeno tende a correr em aproximadamente um terço dos sujeitos (Wever, 1985; Smith et al., 2003). Como veremos mais adiante, tal fenómeno tem sido também associado à realização de trabalho nocturno.

Em condições normais, no entanto, os ritmos circadianos tendem a estar alinhados com os ciclos ambientais, desigando-se ao processo de sincronização dos relógios biológicos pelas influências ambientais, alinhamento ou sincronização externa (Silva et al., 1996; Moore, 1997). Os eventos externos que são capazes de promover tal ajustamento foram designados por Aschoff (1954, 1958) como zeitgeber (palavra alemã que significa "dador do tempo") ou por Halberg e colaboradores (1954) como sincronizadores (Minors \& Waterhouse, 1981). Assim, é através do processo de sincronização que os ritmos circadianos de uma dada espécie se ajustam, exibindo, em condições normais, um período de exactamente de 24 horas. No caso do ser humano, os ritmos circadianos podem ser sincronizados por estímulos fóticos e não fóticos (Wever, 1985; Aschoff \& Wever, 1992; Silva et al., 1996; Moore, 1997; Armstrong, 2000), isto é, pelo ciclo claro-escuro e por factores sociais e comportamentais (hábitos de vida). Assim, variações diárias de intensidade do ruído ambiental, horários das refeições, rotinas domésticas e profissionais ou interacções sociais são exemplos de zeitgebers que alinham os ritmos humanos (Silva et al., 1996; Amostrong, 2000).

Quando o sistema está alinhado, os ritmos circadianos assumem uma relação estável com os zeitgebers, permitindo esse alinhamento a manutenção de uma relação estável dos ritmos circadianos entre si (Moore-Ede \& Sulzman, 1992), em que o sistema temporal circadiano conduz o organismo a uma alternância cíclica ao longo do dia, com desactivação e sonolência na sua fase baixa (algures na segunda parte da noite), e activação fisiológica e comportamental durante a sua fase elevada (com picos no período da tarde). Esta estabilidade das relações de fase entre os diversos ritmos ao 
longo do tempo tem sido considerada como essencial para o bem-estar e para a preservação da saúde dos indíviduos (Minors \& Waterhouse, 1981; Moore-Ede \& Sulzman, 1992; Silva et al., 1996; Armstrong, 2000). Em suma, os ritmos circadianos sob condições normais, embora não sendo gerados pelos factores externos de natureza cíclica que acompanham a alternância noite-dia, são por si influenciados, nomeadamente, no processo de "acerto" (sincronização) do período do sistema temporal endógeno (ou se quisermos, do "relógio biológico") para o período das 24 horas.

Quando os ritmos deixam de estar alinhados com os ciclos externos, diz-se que ocorreu dessincronização externa ou desalinhamento (Silva et al., 1996), constituindo a realização de trabalho nocturno ou a travessia rápida de fusos horários exemplos de situações onde ocorrem alterações bruscas nos zeitgebers. Caso a situação de dessincronização externa persista, pode ocorrer, nalguns indivíduos, dessincronose ou dissociação interna (i.e., perda das relações habituais de fase entre os ritmos biológicos ou, dito de outro modo, perda da ordem temporal interna), fenómeno a que já fizemos referência anteriormente e que tem particular interesse na compreensão de alguns dos problemas experienciados pelos trabalhadores por turnos.

No caso do trabalho por turnos, nomeadamente quando este envolve trabalho nocturno, uma das questões com grande relevância prática é a de saber até que ponto ocorre uma adaptação dos ritmos circadianos à inversão do ciclo de actividade-repouso, decorrente de um horário de trabalho que exige que o indivíduo durma de dia e trabalhe durante a noite. Precisamente com esse intuito, foram realizados diversos estudos laboratoriais e de campo. Considerando o estudo da adaptação do ritmo da temperatura central (usado frequentemente como marcador de fase nos processos de adaptação fisiológica ao trabalho por turnos), os resultados obtidos apontam para uma adaptação incompleta, mesmo após mais de 20 dias consecutivos de estudo (Åkerstedt, 1985). Além da temperatura, foram monitorizados outros ritmos em contexto laboratorial (ex., volume de excreção urinária, potássio). Um traço comum aos estudos laboratoriais que monitorizam diversas funções rítmicas, como salienta Åkerstedt (1985), refere-se ao facto de variáveis diferentes ajustarem-se a velocidades diferentes à inversão de fase. As diferenças de velocidade de ajustamento entre os ritmos, deve-se, presumivelmente, à influência das 
componentes endógenas e exógenas, sendo que quanto mais controlado for o ritmo pelo sistema temporal endógeno, mais lento é o seu ajustamento às mudanças de fase (Minors \& Waterhouse, 1981; Smith et al., 2003). A propósito dos resultados obtidos nos estudos laboratoriais, Åkerstedt (1985) conclui que estes indicam que o processo de ajustamento circadiano se inicia após a primeira noite, ocorrendo muita da mudança durante a primeira semana, não sendo, no entanto, possível concluir-se que tenha havido uma inversão completa ao longo dos períodos considerados (máximo de três semanas). Outros estudos laboratoriais referidos pelo autor (Åkerstedt, 1995 , 2003), indicam, no entanto, que o ajustamento circadiano pode ocorrer, mas somente sob certas circunstâncias, parecendo que o mecanismo reside na exposição à luz numa fase circadiana particular, sendo a velocidade de ajustamento, nessas condições, de cerca de uma hora por dia.

Quanto aos estudos de campo realizados com trabalhadores por turnos, de um modo geral, os resultados obtidos apontam para uma resistência de adaptação fisiológica à inversão do ciclo sono-vigília (ex., temperatura, cortisol, melatonina) (Minors \& Waterhouse, 1981; Åkerstedt, 1985, 1990), embora, também aqui, o grau de adaptação observado dependa das componentes endógenas e exógenas da variável em causa e do tempo de exposição. No entanto, mesmo no caso dos sistemas de turnos com várias semanas de trabalho em sucessão não tem sido observada uma adaptação circadiana completa em ritmos cuja componente endógena é marcada como é o caso do ritmo da temperatura central (Åkerstedt, 1985). Neste contexto, diversos autores (ex., Minors \& Waterhouse, 1981; Folkard, 1992; Knauth, 1996; Costa, 1997; Smith et al., 2003) têm salientado o facto de, mesmo nos turnos nocturnos permanentes, dificilmente existir uma orientação nocturna. Com efeito, mesmo que os trabalhadores estejam submetidos a um turno nocturno permanente, nos seus dias de folga tendem a retomar uma orientação diurna dado ser esta a orientação típica da vida em sociedade. Contrariamente à situação de trabalho nocturno, em que há um desfasamento entre o ciclo sono-vigília e os sincronizadores ambientais e sociais, dificultando a adaptação a esse regime horário, no regresso ao padrão diurno dos dias de folga, todos os sincronizadores podem actuar em consonância para o ajustamento dos ritmos com uma fase apropriada a uma existência diurna (Minors \& 
Waterhouse, 1981; Costa, 1997; Smith et al, 2003). Uma implicação da retoma da orientação diurna nos dias de folga é a de que qualquer adaptação ao trabalho nocturno irá, provavelmente, ser perdida tendo o processo de adaptação que recomeçar (Minors \& Waterhouse, 1981, Åkerstedt, 1990).

O conjunto dos resultados obtidos nos estudos de campo e nos estudos laboratoriais sem manipulação à exposição de luz, indica que a adaptação dos ritmos circadianos ao trabalho nocturno é um processo lento e parcialmente conseguido. Como referem Smith e colaboradores (2003), quando os trabalhadores vão para o turno da noite, a maior parte dos sincronizadores mantém-se constante, desencorajando o ajustamento do sistema circadiano. Por outro lado, o conjunto desses dados indica também que os ritmos circadianos se ajustam a velocidades diferentes à inversão do ciclo de actividade-repouso, embora o grau desse (progressivo) ajustamento, entre outros factores, dependa do tempo de exposição ao trabalho nocturno. Como resultado, as relações de fase normais entre os ritmos circadianos podem "desmoronar-se", conduzindo à perda da ordem temporal interna (Åkerstedt, 1985; Smith et al., 2003). Crê-se que esta dissociação interna ou perturbação da estrutura rítmica circadiana esteja subjacente a várias das queixas experienciadas pelos trabalhadores por turnos a curto prazo, como alterações no sono, alterações de humor, problemas digestivos, diminuição do desempenho ou fadiga (Minors \& Waterhouse, 1981; Comperatore \& Krueger, 1990; Costa, 1996, 1997; Smith et al., 2003; Totterdell, 2005). A este propósito veja-se, por exemplo, a revisão de estudos efectuada por Ashkenazi, Reinberg \& Motohashi (1997) sobre a associação entre dessincronização interna e intolerância ao trabalho por turnos. A presença dos sintomas bem como os níveis da sua intensidade podem variar consideravelmente entre os trabalhadores por turnos, sendo que no caso daqueles considerados clinicamente intolerantes, tipicamente, constam três elementos: fadiga persistente (a qual não desaparece após o sono ou os dias de descanso), alterações de sono (caracterizadas, por exemplo, por dificuldades em adormecer ou despertares frequentes durante o sono, como vermos no ponto seguinte) e uso regular de hipnóticos (Ashkenazi et al., 1997).

A sintomatologia descrita anteriormente é também característica do chamado Síndroma de Jet Lag (o qual, está associado à travessia rápida 
de vários fusos horários), tendo levado alguns autores (ex., Kogi, 1985; Comperatore \& Krueger, 1990; Costa, 2003), a aplicar a expressão Síndroma do "Shift Lag" no contexto da problemática do trabalho por turnos. Embora a perturbação da estrutura circadiana resultante de uma mudança abrupta de fase constitua um elemento comum a ambas as situações, ressalve-se que, contrariamente ao passageiro no novo local (onde todos os sincronizadores estarão em sintonia, encorajando o realinhamento do sistema circadiano), o trabalhador por turnos pode estar sujeito a mudanças contínuas de fase dos sinais de alinhamento (Comperatore \& Krueger, 1990).

Em suma, é indiscutível que o trabalho por turnos inicia o processo de adaptação dos ritmos circadianos à inversão de fase (Åkerstedt, 1985). No entanto, como sublinham Smith e colaboradores (2003), os dados disponíveis indicam de modo claro que o ajustamento do sistema circadiano dos trabalhadores por turnos às mudanças de fase impostas pelo trabalho nocturno é um processo bastante lento, se é que chega a ocorrer uma adaptação completa. De facto, mesmo no caso de trabalhadores nocturnos permanentes, além de haver um desfasamento entre os diversos zeitgebers e o ciclo de actividade-repouso, os trabalhadores tendem a regressar, nos seus dias de folga, a um padrão diurno de actividade, favorecendo a que qualquer ajustamento parcial conseguido possa ser perdido. Na maioria dos casos, é observado um achatamento da amplitude dos ritmos circadianos e uma dessincronização interna entre os parciais ajustamentos das diferentes funções rítmicas (Costa, 1997), embora o grau de (des)ajustamento dependa do número de noites consecutivas trabalhadas bem como de outros factores (ex., grau de compromisso do trabalhador face ao seu horário de trabalho), explicando assim a grande variabilidade interindividual observada. Da descrição deste tópico, a (des)organização da estrutura temporal interna parece pois constituir um elemento incontornável na compreensão das consequências associadas à problemática do trabalho por turnos, em especial ao nível da saúde. Como sintetiza Wedderburn (2000) acerca da influência da ritmicidade na compreensão dos efeitos na saúde do trabalho por turnos: "the root of the problem [shiftwork] is that man is primarily a day-active animal" (p. 1). 


\subsubsection{SONO}

As dificuldades com o sono constituem uma razão comum de abandono do trabalho por turnos (Åkerstedt, 2003), tendo várias revisões de literatura (ex., Mott et al., 1965; Costa, 1996, 1997; Wedderburn, 2000; Åkerstedt, 2003) indicado de modo consistente que o sono diurno dos trabalhadores submetidos a turnos nocturnos, quando comparado com o sono nocturno, tende a ser mais curto e de menor qualidade.

A redução do sono diurno tem sido observada em estudos que recorrem a medidas objectivas, quer em contexto laboratorial quer em ambiente habitual de sono, podendo este ser encurtado até quatro horas (Åkerstedt, 1990, 1995; Kecklund, Åkerstedt \& Lowden, 1997), sendo que a sua duração é quase sempre inferior a sete horas (Knauth \& Rutenfranz, 1981). O trabalho de Åkerstedt e Gillberg (1981) é interessante a este propósito. Estes autores reportam três estudos, onde as condições de avaliação do sono foram distintas: i) questionário de auto-relato junto a uma amostra de mais de 900 maquinistas submetidos a sistemas de turnos rotativos; ii) registo de medidas objectivas em casa dos sujeitos (18 sujeitos do primeiro estudo); iii) registo de medidas em contexto laboratorial (com seis trabalhadores diurnos sem experiência de horários de trabalho irregulares). Os resultados obtidos indicaram que o sono diurno, quando comparado com o sono nocturno, foi, em todos os casos, menor em cerca de 3.5 horas.

Em termos da sua qualidade, o sono diurno, quando comparado com o sono nocturno, tem sido associado a um maior número de queixas (ex., menos recuperador, mais fragmentado). Por exemplo, no estudo acima referido onde foi utilizado o questionário de auto-relato, o turno nocturno, quando comparado com o horário de trabalho diurno, estava associado a uma maior frequência de queixas de sono e de humor. Especificamente, estava associado, por ordem decrescente da frequência das queixas, a maiores dificuldades em manter o sono, a menor valor restaurador do sono, sono perturbado, fadiga no trabalho, dificuldades em adormecer e irritação no trabalho.

Muitos outros estudos empíricos, recorrendo a medidas subjectivas e envolvendo sistemas rotativos (ex., Folkard \& Barton, 1993; Parkes, 1999, 
2002) e trabalho nocturno permanente (ex., Silva C. F., 2000; Ruggiero, 2003; Silva, 2008) têm confirmado que o turno nocturno, quando comparado com turnos diurnos de trabalho, se encontra associado a dificuldades envolvendo a redução e a qualidade de sono. A meta-análise de Pilcher e colaboradores (2000), baseada em 36 estudos empíricos que abordavam a relação entre trabalho por turnos e duração do sono, indicou que os trabalhadores que realizavam trabalho nocturno, fixo ou alternado, em comparação com os trabalhadores diurnos, dormiam menos, especialmente quando submetidos a sistemas rotativos.

No intuito de compensar a redução do sono diurno, a realização de sestas é uma prática frequente, aumentando a sua prevalência à medida que o episódio de sono principal é encurtado (Åkerstedt \& Torsvall, 1985). A revisão de literatura de Åkerstedt (2003) indica que cerca de um terço dos trabalhadores faz uma sesta ao final da tarde entre noites de trabalho sucessivas, com uma duração, frequentemente, superior a uma hora.

Ainda que as condições presentes durante o dia possam contribuir para a disrupção do sono (ex., maiores níveis de ruído oriundos do exterior e/ ou do interior da habitação), há consenso de que as dificuldades se devem, principalmente, à deslocação temporal dos horários de sono (Lavie, 2001), sendo este realizado num período em que está fora de fase com muitos ritmos circadianos (Åkerstedt \& Gillberg, 1981; Costa, 1997; Åkerstedt, 2003; Smith et al., 2003). Como vimos anteriormente, o sono diurno é encurtado, mesmo quando realizado em contexto laboratorial, ou seja, num contexto em que o sono é protegido das influências do meio externo capazes de o perturbar. Outros estudos laboratoriais referidos por Åkerstedt (1995), com trabalhadores por turnos rotativos, apontam também para uma redução do sono diurno, resultados que evidenciam a relevância dos factores circadianos neste tipo de perturbação. Como sublinham Smith e colaboradores (2003), os trabalhadores por turnos que necessitam de dormir durante o dia podem ter dificuldades em adormecer e em manter o sono dado que se estão a esforçar por dormir num período desajustado, relativamente aos seus ritmos circadianos. Ou, como referem Minors e Waterhouse (1981), o trabalhador está a tentar dormir num período em que o seu organismo pode estar a preparar-se para um novo dia. 
Ainda que os estudos, nomeadamente os polissonográficos, sejam mais escassos (Kecklund et al., 1997), existe evidência de que o turno da manhã com início muito cedo também se encontra associado a problemas de sono. Por exemplo, a revisão efectuada por Knauth e Rutenfranz (1981) indicou, à semelhança do que se verificava para o turno da noite, uma duração do sono inferior a sete horas na maioria dos casos afectos ao turno da manhã. Mais recentemente, Kecklund e colaboradores (1997), com base em medidas subjectivas e em registos polissonográficos efectuados em casa dos sujeitos, verificaram que a duração média do sono no grupo de controlo (início do ciclo de trabalho a partir das 8h30), era superior a sete horas em ambas as condições de avaliação (dias de trabalho e dias de folga) enquanto que no grupo correspondente ao turno da manhã (início do ciclo de trabalho antes das 6h30), essa duração situava-se, em média, nas 7 horas e 7 minutos no período de folga e nas 5 horas e 12 minutos no período de trabalho, envolvendo tal encurtamento uma menor duração da fase 2 e do sono REM (Rapid Eye Movement). Os resultados obtidos neste estudo são congruentes com outros estudos polissonográficos mencionados por Åkerstedt (1995) com trabalhadores por turnos rotativos; à semelhança do que ocorre com o sono afecto ao turno da noite, o sono afecto ao turno da manhã, com início muito cedo, pode ser encurtado até quatro horas, envolvendo esse encurtamento, primariamente, a fase 2 do sono e o sono REM. Outros estudos empíricos, recorrendo apenas a medidas subjectivas (ex., Folkard \& Barton, 1993; Ohayon, Lemoine, Arnaud-Briant \& Dreyfus, 2002), evidenciam, igualmente, que o turno da manhã, quando iniciado muito cedo, se encontra associado a dificuldades acrescidas com o sono. Åkerstedt (2003) refere mesmo que as dificuldades relacionadas com o acordar de manhã tornam este turno, frequentemente, o menos popular dos três turnos.

As dificuldades de sono relativas ao turno da manhã são igualmente melhor compreendidas se se integrar a influência dos factores circadianos, para além da influência de factores do meio (ex., obrigações domésticas e/ ou "pressão" para conviver familiar e socialmente) que possam atrasar o horário de deitar. Assim, mesmo que um indivíduo se esforce por deitar mais cedo, poderá confrontar-se com dificuldades em iniciar o sono dado que está a deslocar o seu horário de dormir para um período próximo da 
acrofase circadiana (Åkerstedt et al., 1992, citados por Åkerstedt 2003) ou, dito de outro modo, próximo do "pico" da activação circadiana, período durante o qual a propensão para o sono é substancialmente reduzida (Folkard \& Barton, 1993). Face às dificuldades descritas, a realização de sestas é também um comportamento frequente no caso deste turno. Com efeito, a revisão de Åkerstedt (2003) indicou que cerca de um terço dos trabalhadores afectos a este turno a praticam.

Em síntese, ainda que as perturbações no sono dos trabalhadores afectos ao turno da noite e da manhã com início muito cedo possam também ser explicadas por condições situacionais desfavoráveis, elas ficam a dever-se principalmente a "interferências" circadianas, resultando, frequentemente, num sono curto, fragmentado e com menor valor restaurador.

\subsection{CONSEQUÊNCIAS NA SAÚDE}

Neste ponto revemos os principais efeitos do trabalho por turnos em termos de saúde. Assim, começamos por apresentar a evidência disponível em termos de saúde psicológica, seguindo-se-lhe as consequências no sistema gastrointestinal, no sistema cardiovascular e a apresentação dos riscos acrescidos que a literatura tem indicado no caso das mulheres, sobretudo relacionados com a saúde reprodutiva. Concluímos com a evidência recente (e crescente) que aponta para a relação entre a exposição ao trabalho nocturno e o maior risco de desenvolvimento de cancro, especialmente cancro da mama.

\subsubsection{SAÚDE PSICOLÓGICA}

Embora a relação entre trabalho por turnos e psicopatologia seja uma área subinvestigada (Cole, Loving \& Kripke, 1990; Wedderburn, 2000), há certa evidência que os trabalhadores por turnos, especialmente se realizam trabalho nocturno, em comparação com os trabalhadores diurnos, apresentam uma maior incidência de perturbações, referidas na literatura, frequentemente, como perturbações "neuróticas". 
Com base numa amostra de mais de 500 operários têxteis do sexo masculino, distribuídos por quatro grupos - horário diurno, sistema de dois turnos (manhã e tarde), sistema de três turnos (manhã, tarde e noite, de rotação semanal) e nocturno fixo - Costa, Apostoli, d'Andrea e Gaffuri (1981) avaliaram a incidência de desordens "neuróticas" e gastrointestinais no respectivo horário de trabalho. No que respeita às desordens "neuróticas", estas foram definidas através da presença de sintomatologia ansiosa e depressiva, exigindo tratamento farmacológico por um período superior a três meses ou hospitalização. Os resultados indicaram que a incidência foi bem mais elevada nos trabalhadores nocturnos fixos, em especial nos primeiros anos de experiência nesse regime horário. Enquanto que a incidência observada nesse regime foi de $64.4 \%$, nos restantes foi de $22.1 \%$ (sistema de três turnos), 9.4\% (sistema de dois turnos) e 3.9\% (horário diurno).

Num dos estudos realizados por Koller e colaboradores (1981), foram entrevistados todos os doentes admitidos num hospital universitário psiquiátrico ao longo de quatro meses. A proporção de doentes que haviam trabalhado por turnos ou horários irregulares antes da admissão foi mais elevada do que aquela que seria esperada para a população em geral, tendo essa diferença sido estatisticamente significativa para os trabalhadores nocturnos ocasionais, mas não para os trabalhadores nocturnos permanentes. Um outro estudo realizado pela mesma equipa de investigação, baseando-se numa amostra de 200 doentes hospitalizados e diagnosticados com um quadro depressivo, não foram observadas diferenças significativas entre a população geral e a população trabalhadora por turnos. No entanto, a frequência foi mais elevada entre aqueles indivíduos que se encontravam sujeitos a horários de trabalho irregulares. Refira-se, no entanto, que os indivíduos diagnosticados com depressão e que sofressem, concomitantemente, de outras perturbações mentais ou de alcoolismo foram excluídos da amostra, o que poderá ter reduzido o número de casos na população trabalhadora por turnos. De facto, tem sido assinalada a associação entre trabalho por turnos e abuso de álcool (Cole et al., 1990).

Diversos estudos têm também associado o trabalho por turnos, especialmente em conexão com o trabalho nocturno, a uma avaliação subjectiva da diminuição do bem-estar geral. No leque alargado de queixas subjectivas 
relatadas pelos trabalhadores por turnos, têm sido incluídas irritabilidade, impulsividade, "nervosismo", "dores de cabeça", palpitações, tremores nas mãos, tensão muscular, sonolência, "olhos cansados", dificuldades nas relações sexuais, diminuição da concentração ou maiores níveis de fadiga (Åkerstedt \& Gillberg, 1981; Zedeck, Jackson \& Summers, 1983; Cole et al., 1990), podendo algumas destas queixas ser interpretadas como sinais de depressão (Cole et al., 1990). Outros estudos (ex., Bohle \& Tilley, 1989, 1993; Silva, 1999), têm avaliado o impacto do trabalho nocturno no humor, recorrendo para o efeito a medidas de auto-relato.

Com base também em medidas de auto-relato, Ruggiero (2003) avaliou se existiam diferenças entre um grupo de enfermeiras submetidas ao horário de trabalho diurno fixo (grupo diurno) e um grupo de enfermeiras submetidas ao horário de trabalho nocturno permanente (grupo nocturno) em termos de depressão, ansiedade, qualidade global de sono e fadiga crónica. As profissionais do grupo nocturno, em comparação com as profissionais do grupo diurno, apresentaram de modo significativo, maiores níveis de depressão e de problemas de sono. Porém, em termos de ansiedade e de fadiga crónica não foram encontradas diferenças estatisticamente significativas entre os dois grupos.

Pelos estudos descritos anteriormente, embora em número escasso, podemos verificar a variabilidade de métodos que têm sido usados na avaliação de problemas psicopatológicos. Esta variabilidade de métodos tem sido referida (ex., Costa, 1996; Wedderburn, 2000) como uma das principais dificuldades na obtenção de uma avaliação rigorosa da extensão e da gravidade das perturbações neste domínio. Na sequência desta lacuna tem sido sublinhada a necessidade da comunidade científica adoptar medidas de avaliação estandardizadas, realizar estudos de natureza longitudinal e utilizar critérios de diagnóstico bem estabelecidos (ex., Manual de Diagnóstico e Estatística das Perturbações Mentais, DSM) (Cole et al., 1990; Costa, 1996).

No global, os resultados disponíveis apontam para o facto dos trabalhadores por turnos, particularmente quando submetidos a trabalho nocturno, apresentarem, em comparação com os trabalhadores diurnos, mais queixas relacionadas com o sono, fadiga e sintomatologia ansiosa e depressiva. Em virtude dessas dificuldades tem sido referido um maior consumo de fármacos 
por parte dos trabalhadores por turnos, principalmente, hipnóticos e tranquilizantes (Cole et al., 1990; Wedderburn, 2000). Por outro lado, ainda que os estados psicológicos e emocionais dos trabalhadores por turnos sejam frequentemente avaliados em estudos empíricos, as perturbações na saúde física têm, comparativamente, atraído mais atenção. No entanto, é provável que uma parte substancial dos trabalhadores que decidem abandonar o regime de trabalho por turnos o faça devido ao stress psicológico resultante desse regime horário (Smith et al., 2003). Do ponto de vista dos mecanismos envolvidos nas queixas de saúde psicológica, tem sido referido que estas resultam, por um lado, da perturbação dos ritmos circadianos, donde se salienta a perturbação do ritmo sono-vigília e, por outro, da interferência do regime de trabalho por turnos com os papéis familiares e sociais (Wedderburn, 2000).

\subsubsection{SISTEMA GASTROINTESTINAL}

Perturbações no apetite, dispepsia, azia, obstipação, flatulência, dores de estômago ou dores abdominais são queixas bastante comuns entre os trabalhadores por turnos (Barton et al., 1995; Costa, 1996, 1997, Knutsson, 2003), sobretudo aquando da mudança do trabalho diurno para o nocturno (Mott et al., 1965; Costa, 1996). A revisão de Costa (1996) indica que a incidência deste tipo de problemas se situa entre 20 a $75 \%$ no caso dos trabalhadores nocturnos (permanentes ou rotativos), enquanto que no caso dos trabalhadores sem trabalho nocturno (diurnos ou trabalhadores por turnos) oscila entre 10 a 25\%. Tais problemas, como refere o autor, podem evoluir em muitos casos para doenças mais graves como gastrite crónica ou úlceras pépticas.

O estudo de Costa e colaboradores (1981) com operários têxteis a que já fizemos referência, avaliou também a incidência de desordens gastrointestinais (gastroduodenites e úlceras pépticas), tendo a formulação do diagnóstico sido baseada em exames clínicos e na avaliação sintomatológica (no caso das gastroduodenites). Os resultados indicaram que os trabalhadores nocturnos - fixos ou rotativos - quando comparados com os outros 
trabalhadores (diurnos e sistema de dois turnos), apresentavam de modo significativo uma maior incidência em ambas as patologias. Verificaram também que a incidência de gastroduodenites era maior nos primeiros anos de experiência de trabalho por turnos e entre indivíduos mais jovens, enquanto que o desenvolvimento de úlceras pépticas tendia a ocorrer em sujeitos de meia idade, com mais de oito anos de experiência de trabalho por turnos, ainda que, neste caso, não tenham sido registadas diferenças significativas do ponto de vista estatístico. Entre os trabalhadores que a dada altura abandonaram o trabalho nocturno, uma percentagem significativa fê-lo devido a problemas gastrointestinais, nomeadamente, 67\% dos trabalhadores que haviam trabalhado no sistema rotativo e 23\% dos trabalhadores nocturnos fixos.

Dos trinta e seis estudos epidemiológicos revistos por Costa (1996), envolvendo no conjunto cerca de 98400 trabalhadores de diversos sectores de actividade, vinte e cinco indicaram uma maior prevalência de desordens gastrointestinais (incluindo úlceras pépticas) nos trabalhadores por turnos, quando comparados com trabalhadores diurnos. Considerando os estudos onde foi estimada a incidência de úlceras pépticas, verifica-se que esta é superior, entre 2 a 5 vezes, no caso dos trabalhadores nocturnos (de modo fixo ou alternado), quando comparada com a incidência nos trabalhadores cujos horários de trabalho não exigem a realização de trabalho nocturno. Dos restantes onze estudos revistos, em dez não foram encontradas diferenças significativas entre trabalhadores por turnos e trabalhadores diurnos nas desordens gastrointestinais, tendo apenas um deles verificado uma maior incidência destas nos trabalhadores diurnos.

Os mecanismos explicativos da relação entre trabalho por turnos e o desenvolvimento de desordens gastrointestinais não são claros, sendo a situação mais provável, no entanto, aquela que deriva da combinação entre vários factores, incluindo factores respeitantes ao relógio biológico e ao regime alimentar (Barton et al., 1995). Assim, uma das explicações dadas prende-se com o desfasamento entre os horários das refeições e as fases circadianas das funções gastrointestinais (ex., secreção gástrica, actividade enzimática, mobilidade intestinal), resultante da inversão do ciclo normal sono-vigília (Vener et al., 1989, citados por Costa, 1997). Como referem 
Barton e colaboradores (1995), é possível que não ocorra uma adaptação das funções gástricas ao trabalho nocturno, podendo a ingestão de alimentos durante esse período exacerbar os problemas gástricos. Outras explicações têm-se centrado em aspectos relativos à alimentação, nomeadamente em termos de frequência e de composição das refeições. Embora a quantidade de calorias pareça não sofrer alterações (Costa, 1996), o mesmo não tende a acontecer com o número e a qualidade das refeições aquando da mudança para o turno nocturno, sendo frequente a omissão ou o aligeirar de algumas refeições, a par de um maior consumo de bebidas estimulantes (ex., café, chá) e/ou de tabaco para lidar com a diminuição da vigília durante o período de trabalho (Costa, 1996, 1997).

Com o intuito de elucidar possíveis mecanismos relativos à associação entre trabalho por turnos e perturbações na saúde, Kivimäki, Kuisma, Virtanen e Elovainio (2001) examinaram a relação entre o tipo de horário de trabalho e determinados comportamentos, nomeadamente consumo de tabaco, consumo de álcool, excesso de peso e estilo de vida sedentário. Foram comparados dois grupos de enfermeiras em função dos horários praticados ao longo da sua vida profissional: um grupo constituído por profissionais sem qualquer experiência de trabalho por turnos e outro, cujas profissionais sempre haviam trabalhado em regime de turnos. No que respeita ao consumo de álcool e ao estilo de vida sedentário não foram encontradas diferenças estaticamente significativas entre ambos os grupos. No entanto, o trabalho por turnos encontrava-se associado a um maior consumo de tabaco e de excesso de peso, diferenças que se acentuavam à medida que aumentava a idade, especialmente a partir dos 45 anos. O estudo de van Amelsvoort e Kok (1999), com cerca de 370 trabalhadores diurnos e por turnos (limitados a trabalhadores em sistemas rotativos com noites), encontrou igualmente uma associação positiva entre a duração da exposição ao trabalho por turnos e um risco acrescido de obesidade, avaliada através do índice de massa corporal e da obesidade abdominal, para ambos os sexos. Em que medida tal relação reflecte uma mudança dos hábitos alimentares ou aspectos metabólicos, como referem os autores, ainda não é claro.

Os trabalhadores, em particular os que realizam noites, quando comparados com os trabalhadores cujo horário de trabalho é diurno, exibem uma 
maior frequência de queixas e de doenças do aparelho gastrointestinal, levando Knutsson (2003) a concluir que existe uma forte evidência que associa horário de trabalho por turnos a úlceras pépticas. Do ponto de vista dos mecanismos envolvidos, Totterdell (2005) refere que são várias as explicações possíveis, incluindo mudanças nas funções neuroendócrinas associadas à mudança de padrões de sono e mudanças no conteúdo e nos horários das refeições.

\subsubsection{SISTEMA CARDIOVASCULAR}

Após anos de discussão, a maioria dos investigadores reconhece, actualmente, que existe uma relação entre trabalho por turnos e desordens cardiovasculares (Smith et al., 2003). Embora haja um conjunto de dados empíricos disponíveis que suportam essa relação (Knutsson, 2003), os seus mecanismos explicativos carecem de maior investigação (Boggild \& Knutsson, 1999; Boggild, Burr, Tüchsen \& Jeppesen, 2001; Karlsson, Knutsson \& Lindahl, 2001).

Porventura um dos estudos mais citado neste domínio diz respeito ao estudo longitudinal realizado por Knutsson, Åkerstedt, Jonsson e Orth-Gomer (1986), tendo este sido realizado ao longo de 15 anos e envolvendo um grupo de 394 operários submetidos a um sistema rotativo de três turnos e outro de 110 trabalhadores diurnos fixos, ambos compostos por indivíduos do sexo masculino. Quando os dois grupos foram comparados sem considerar o tempo de exposição, o risco relativo de desenvolvimento de doenças cardiovasculares nos trabalhadores por turnos foi de 1.4 e não significativo. Porém, quando se considera o tempo de exposição ao trabalho por turnos, verifica-se que o risco relativo aumenta à medida que aumenta o tempo de exposição durante as primeiras duas décadas de exposição, independentemente da idade, tendo esse risco sido significativo para os períodos de exposição compreendidos entre 11 e 15 anos e entre 16 e 20 anos.

Numa revisão mais recente de 17 estudos epidemiológicos sobre trabalho por turnos e desordens cardiovasculares, Boggild e Knutsson (1999) estimaram que os trabalhadores por turnos, de ambos os sexos, tinham um 
risco acrescido de 40\% no desenvolvimento de doenças cardiovasculares, quando comparados com os trabalhadores diurnos. Não obstante a estimativa geral, quatro dos estudos não encontraram uma associação entre as duas variáveis e, entre aqueles que incluíram a avaliação do risco em função do tempo de exposição, os resultados foram mistos, tendo apenas dois dos quatro estudos suportado uma relação dose-resposta (i.e., quanto maior a exposição, maior o risco). Os autores reconhecem que a diversidade de estudos pode ter tornado a meta-análise problemática, embora, concluam, que a estimativa mais aceitável continua a ser aquela que se situa num risco relativo de 1.4 , tendo sido essa, aliás, a estimativa derivada do estudo de Knutsson e colaboradores (1986), estudo por eles considerado o mais convincente do ponto de vista metodológico até ao momento.

Em termos da compreensão da associação entre trabalho por turnos e desordens cardiovasculares têm sido propostos vários mecanismos inter-relacionados, incluindo perturbação dos ritmos circadianos, alterações bioquímicas, perturbação social e mudanças comportamentais (Boggild \& Knutsson, 1999). A este propósito, Costa (1996, 1997) refere que a situação de stress provocada pelo regime de trabalho por turnos pode ter efeitos no sistema cardiovascular através de influências directas e indirectas. As primeiras relacionam-se com a activação neurovegetativa e neurohormonal, em relação com comportamentos de coping, com o aumento de catecolaminas e cortisol e seus efeitos subsequentes na pressão sanguínea, taxa cardíaca, processos trombócitos, lipídios e metabolismo da glicose. As influências indirectas, globalmente, dizem respeito aos contextos de trabalho e de vida mais stressantes a que os trabalhadores por turnos possam estar expostos.

A nível comportamental, alguns estudos comparativos entre trabalhadores por turnos e trabalhadores diurnos têm apontado para algumas diferenças, especialmente ao nível do consumo de tabaco. Dos treze estudos revistos por Boggild e Knutsson (1999), em seis foi verificado que os trabalhadores por turnos consumiam, de modo significativo, mais tabaco que os trabalhadores diurnos, um dos estudos verificou a situação inversa e os restantes não encontraram quaisquer diferenças. O estudo de Kivimäki e colaboradores (2001), a que já fizemos referência anteriormente, encontrou também diferenças significativas entre ambos os grupos no consumo de tabaco e 
no excesso de peso, tendo estes sido maiores no caso das enfermeiras que trabalhavam por turnos, especialmente a partir dos 45 anos de idade. Os resultados obtidos no estudo epidemiológico de Karlsson e colaboradores (2001), envolvendo mais de vinte e sete mil trabalhadores, indicaram também que o trabalho por turnos em comparação com o trabalho diurno, estava associado a uma maior prevalência de obesidade e a maiores concentrações de triglicéridos, enquanto que ao nível da hipertensão não foram encontradas diferenças entre os dois regimes horários.

Outros estudos (ex., Peter \& Siegrist, 1999; Peter, Alfredsson, Knutsson, Siegrist \& Westerholm, 1999; Boggild et al., 2001; Virtanen \& Notkola, 2002) têm procurado avaliar factores relativos ao contexto ocupacional e extra-ocupacional que possam contribuir para a compreensão da associação entre trabalho por turnos e desenvolvimento de desordens cardiovasculares como, por exemplo, a latitude de decisão. Ao nível das condições de vida mais genéricas, há evidência de que os trabalhadores por turnos tendem a ser oriundos de classes sócio-económicas mais baixas (Boggild \& Knutsson, 1999) e de que este tipo de variável se relaciona com as taxas de mortalidade devidas a desordens cardiovasculares (Virtanen \& Notkola, 2002).

Concluindo, a evidência disponível sugere fortemente, como referem Smith e colaboradores (2003), que o trabalho por turnos constitui um factor relevante no desenvolvimento de desordens cardiovasculares, sendo a natureza da etiologia envolvida, porém, complexa e multifacetada.

\subsubsection{SAÚDE REPRODUTIVA}

O trabalho por turnos tem sido associado a diversos efeitos negativos na saúde reprodutiva das mulheres (Costa, 1996; Nurminen, 1998; Knutsson, 2003). Neste domínio, os abortos espontâneos, os nascimentos prematuros e o impacto no crescimento intra-uterino têm sido os efeitos mais estudados (Nurminen, 1998). Perturbações no ciclo menstrual (ex., irregularidade, dores menstruais) têm sido igualmente referidas na literatura (Costa, 1996, 1997; Wedderburn, 2000; Labyak, Lava, Turek \& Zee, 2002), particularmente quando estão envolvidos sistemas de turnos rotativos (Wedderburn, 2000). 
Ainda que se presuma que os efeitos na saúde reprodutiva derivados da exposição ao trabalho por turnos possam estar, directa ou indirectamente relacionados com as perturbações hormonais (Nurminen, 1998; Smith et al., 2003), no global, a compreensão dos mecanismos envolvidos é pobre (Nurminen, 1998; Labyak et al., 2002). Neste contexto, tem sido sugerida a acção das perturbações do sono (ex., Labyak et al., 2002) e do stress psicossocial como possíveis mecanismos indirectos (ex., Mozurkewich, Luke, Avni \& Wolf, 2000).

A revisão da literatura de Nurminen (1998) aborda especificamente a relação entre trabalho por turnos e saúde reprodutiva. Embora os estudos epidemiológicos revistos nem sempre apresentem definições claras do que é considerado trabalho por turnos e incluam uma grande variedade de arranjos horários, na maioria dos casos, os horários de trabalho envolvidos nos efeitos detectados correspondem a sistemas rotativos, horário nocturno fixo e horários irregulares. Os aspectos considerados na revisão do ponto de vista da saúde reprodutiva foram: período de tempo que demorou a alcançar a gravidez, grau de regularidade do ciclo menstrual, abortos espontâneos, nascimentos prematuros e crescimento intra-uterino. Em relação ao período de tempo em que a mulher demorou a ficar grávida, três dos cinco estudos revistos indicam um efeito negativo da exposição ao trabalho por turnos, em comparação com o trabalho diurno fixo, especialmente quando estão envolvidos sistemas de turnos rotativos; dois dos estudos, no entanto, não evidenciam tal relação. Quanto à irregularidade dos ciclos menstruais, os três estudos considerados na revisão apontaram para uma associação positiva com o trabalho nocturno (dois estudos) e com os horários de trabalho irregulares sem trabalho nocturno (um estudo). Quanto ao aumento de risco de aborto espontâneo em relação com o trabalho por turnos e nocturno, sete dos nove estudos revistos apoiaram essa associação e dois deles não, embora os dois últimos envolvessem a realização de trabalho nocturno. No que respeita a um risco acrescido de nascimentos prematuros em conexão com o trabalho por turnos, quatro dos cinco estudos revistos sugerem essa relação, especialmente quando está envolvida alguma forma de trabalho nocturno. Adicionalmente, alguns dos estudos referidos na dimensão anterior têm 
sugerido uma relação entre exposição a trabalho por turnos (especialmente sistemas rotativos) e atrasos no desenvolvimento intra-uterino; um dos estudos, porém, não apoiou essa associação.

Não obstante os resultados mistos encontrados, a revisão da literatura anterior sugere, globalmente, que o trabalho por turnos representa um potencial factor de risco ao nível da saúde reprodutiva, sendo tal associação mais evidente no caso dos abortos espontâneos e dos nascimentos prematuros. Como conclui a autora, apesar da evidência não ser ampla e permanecer ambígua em diversas áreas, é prudente considerar-se este tipo de horário de trabalho como um potencial factor de risco ao nível da função reprodutora.

Os resultados de uma meta-análise mais recente levada a cabo por Mozurkewich e colaboradores (2000) são convergentes com os resultados apresentados por Nurminen (1998) quanto ao impacto negativo do trabalho por turnos em termos dos nascimentos prematuros e, nesse sentido, reforça a importância de se considerar esse tipo de horário de trabalho como um potencial factor de risco ao nível da saúde reprodutiva, pelo menos, neste domínio concreto. Como sublinha Knutsson (2003), mesmo na ausência de provas futuras, parece pois prudente evitar a exposição das mulheres a este risco ocupacional durante o período de gravidez.

\subsubsection{DOENÇA ONCOLÓGICA}

Tem-se verificado recentemente um crescente interesse na possibilidade das perturbações nos ritmos circadianos poderem contribuir para o aumento do risco de cancro bem como dos factores ambientais que poderão contribuir para essa perturbação (ex., trabalho por turnos, Jet Lag crónico, exposição a campos magnéticos) (Davis \& Mirick, 2006; Moser, Schaumberger, Schernhammer \& Stevens, 2006). No que diz respeito aos horários de trabalho como potencial factor de risco, estudos bastante recentes têm apontado para uma relação entre a realização de trabalho nocturno e um maior risco de cancro, nomeadamente, cancro da mama (Hansen, 2001; Megdal, Kroenke, Laden, Pukkala \& Schernhammer, 2005). 
Na recente meta-análise de Megdal e colaboradores (2005) sobre os efeitos do trabalho nocturno no risco do cancro da mama, foi estimado um risco relativo global de 1.48 (95\% de Intervalo de Confiança, 1.36-1.61). Esta meta-análise envolveu treze estudos, sete com hospedeiras e seis com populações trabalhadoras por turnos. Como salientam Moser e colaboradores (2006), até ao momento, exceptuando o caso de outros cancros (ex., consumo de tabaco e risco acrescido de cancro de pulmão), nenhum outro tipo de factor ambiental tinha sido identificado como podendo constituir, nesta magnitude, um factor de risco no desenvolvimento do cancro da mama.

Do ponto de vista dos mecanismos envolvidos na associação entre a exposição ao trabalho nocturno e risco acrescido de desenvolvimento de cancro da mama crê-se que o ritmo circadiano da melatonina desempenha uma acção importante, directa e indirectamente. O pico desta hormona, segregada pela glândula pineal, em condições normais, situa-se, tipicamente, algures a meio do sono, sendo que a sua síntese e libertação é influenciada pelos níveis de exposição à luz (i.e., informação fótica oriunda da retina). O racional subjacente é o de que a perturbação na produção normal desta hormona (i.e., redução dos seus níveis) possa influenciar os perfis de outras hormonas, nomeadamente, as envolvidas na função reprodutora (ex., aumento dos níveis de estrogénio), havendo indicação de que tal ocorrência se encontra associada ao aumento de risco de cancro da mama (Hansen, 2001; Davis \& Marick, 2006). Por outro lado, diversos estudos experimentais e in vitro têm indicado uma relação entre níveis de melatonina e risco de cancro, incluindo um efeito "protector" (ex., retardamento no crescimento do tumor) (ver a este propósito, por exemplo, as revisões de Hansen, 2001 e de Moser et al., 2006).

Em síntese, há um acumular de evidência no sentido de suportar a relação entre risco de cancro (especialmente, cancro da mama) e certos factores ambientais, como é o caso do trabalho nocturno. Não obstante a perspectiva promissora (e preocupante) desta via na compreensão da etiologia do processo de desenvolvimento do cancro da mama, diversos autores (ex., Hansen, 2001; Moser et al., 2006) têm salientado a premência na continuidade de esforços de investigação neste campo. De um modo geral, as 
necessidades elencadas vão no sentido de: i) identificar outros factores (ambientais e internos) que possam interagir com o horário de trabalho, ritmo da melatonina e risco de cancro (ex., ritmo do cortisol); ii) estender o estudo da influência do ritmo da melatonina à compreensão de outros tipos de cancro e envolvendo outro tipo de populações, como a masculina; iii) identificar se existem aspectos dos sistemas de turnos (i.e., timings das mudanças entre turnos) que possam influenciar os níveis de melatonina.

\subsection{CONSEQUÊNCIAS NAS ESFERAS FAMILIAR E SOCIAL}

As diferentes horas do dia não são "equivalentes", sendo que as horas correspondentes ao final da tarde (evening) e ao de fim-de-semana são as mais valorizadas, familiar e socialmente (Baker, Ferguson \& Dawson, 2003; Gadbois, 2004). Com efeito, diversos estudos que têm utilizado diários de ocupação do tempo indicam um padrão de actividade que acompanha os ritmos circadianos, inscritos, por sua vez, em ciclos semanais e sazonais (Walker, 1985). A diferenciação das compensações financeiras em função dos diferentes períodos de trabalho (ex., domingo, feriados) reflecte, igualmente, essa valorização diferencial do tempo (Wedderburn, 1981; Walker, 1985; Baker et al., 2003).

Com base na exposição anterior, é possível, antecipar desde já, certas dificuldades do ponto de vista familiar e social para certos grupos de trabalhadores, nomeadamente quando estão envolvidos sistemas de turnos que incluem trabalho realizado aos fins-de-semana, ao final da tarde, durante a noite e quando envolvem irregularidade nos horários de trabalho, dada a maior dificuldade no planeamento de actividades não individuais. Por outro lado, também se torna possível antecipar, desde já, algumas vantagens associadas a este tipo de horário de trabalho como, por exemplo, uma maior facilidade de acesso a serviços cujo horário de funcionamento se encontre limitado ao horário convencional bem como a complexa teia de variáveis que este domínio envolve, passando pelos interesses pessoais dos trabalhadores por turnos até à prevalência deste modo de organização do horário de trabalho numa dada comunidade. 


\subsubsection{ESFERA FAMILIAR}

De um modo geral, as consequências associadas ao trabalho por turnos na esfera familiar têm envolvido dois tipos de questões: uma relativa às relações entre os membros da família (relações maritais e parentais) e outra relativa à organização da vida doméstica.

Tendo como base uma amostra de mais de mil trabalhadores por turnos do sexo masculino, Mott e colaboradores (1965) avaliaram os efeitos do trabalho por turnos em várias dimensões da vida familiar. Assim, partindo da abordagem dos papéis, os autores analisaram em que medida determinado turno facilitava ou interferia com o desempenho de vários papéis no contexto familiar em comparação com o horário diurno fixo, considerando a perspectiva de ambos os membros do casal. À excepção da vida doméstica, a qual, genericamente, beneficiava com o horário de trabalho por turnos, os restantes aspectos - proporcionar companhia e protecção ao cônjuge, apoio na vida doméstica, proporcionar momentos de convívio e de tomadas de decisão conjunta ou relações sexuais - foram avaliados de modo mais negativo, em especial entre aqueles trabalhadores que desejavam mudar de horário de trabalho. Quanto à perspectiva das esposas, os resultados apontam também para o facto do horário de trabalho por turnos, quando comparado com o horário diurno, dificultar aspectos como relações sexuais, proporcionar companhia e suporte emocional ao cônjuge ou levar a cabo certas tarefas domésticas.

Outros estudos (ex., Staines \& Pleck, 1984; Fenwick \& Tausig, 2001; Demerouti, Geurts \& Bakker, 2004), têm verificado que os horários de trabalho que implicam trabalhar aos fins-de-semana e em que os dias de trabalho são variáveis estão associados a menos tempo na realização dos papéis familiares (especialmente no tempo dedicado ao cuidado dos filhos) e a maiores níveis de conflito trabalho-família, em comparação com o horário de trabalho diurno fixo.

Os estudos mais antigos acerca do impacto do trabalho por turnos na vida familiar focam-se, tipicamente, nos maridos como trabalhadores por turnos e nas esposas como domésticas (Presser, 2000). Face a esta constatação tem sido referida a necessidade de melhor se compreender o impacto 
dos horários de trabalho considerados não standard, incluindo o trabalho por turnos no sistema familiar (ex., Staines \& Pleck, 1984; Presser, 1994, 2000; Gadbois, 2004) dadas as mudanças societais que aconteceram nas últimas décadas, como é o caso do aumento de casais de dupla carreira.

Uma das implicações que tem sido referida no âmbito do aumento de casais de dupla carreira, especialmente com crianças, prende-se com o aumento da intensidade do trabalho nestes agregados (Fagan, 2001a). Neste contexto, alguns autores (Wedderburn, 1981; Walker, 1985; Presser, 1994) têm discutido até que ponto o aumento da diversidade de horários de trabalho não standard no seio familiar, decorrente do aumento da participação das mulheres no mercado de trabalho, poderá contribuir para uma divisão sexual mais igualitária do trabalho doméstico, embora a literatura específica nesta matéria se paute por uma grande escassez (a este propósito, sugere-se a consulta da análise efectuada por Presser, 1994).

Ainda no âmbito das relações conjugais, uma das questões que também tem sido abordada refere-se ao facto do horário de trabalho por turnos poder estar associado a um risco acrescido de divórcio/separação (White \& Keith, 1990; Presser, 2000), podendo este efeito, como refere Presser (2000), ser bi-direccional, sendo que os trabalhadores cujas relações sejam menos estáveis poderão optar por horários de trabalho menos convencionais, embora os dados da autora sugiram a direcção contrária. Os estudos neste domínio pautam-se pela escassez e fragmentação (Presser, 2000), não tendo os resultados produzidos evidenciado padrões claros. Com efeito, a revisão da literatura efectuada por esta autora, onde se procura relacionar os determinantes do divórcio e os aspectos temporais da relação de emprego, aponta para um conjunto multifacetado dos primeiros, englobando factores de natureza estrutural, demográfica e interpessoal. A investigação de Presser (2000) reflecte de algum modo, a teia de variáveis em jogo, nomeadamente a duração da relação marital, a presença ou não de crianças no agregado familiar e o sexo dos cônjuges. Por exemplo, além do turno nocturno fixo, os horários rotativos encontravam-se associados a uma maior probabilidade de separação, mas apenas no caso das mulheres.

No contexto da vida familiar, outros estudos têm procurado avaliar o impacto do trabalho por turnos ao nível das relações e papéis parentais. 
O estudo de Mott e colaboradores (1965), mencionado anteriormente, indicou que os trabalhadores por turnos, em comparação com os diurnos, se sentiam menos capazes de acompanhar as tarefas escolares dos seus filhos, de proporcionar-lhes companhia e de lidar com questões relativas ao controlo e à disciplina.

Estudos mais recentes (Volger, Ernst, Nachreiner \& Hänecke, 1988; Barton, Aldridge \& Smith, 1998) têm também avaliado o impacto do trabalho por turnos nas relações com os filhos. Por exemplo, no estudo de Volger e colaboradores (1988), foi observado que no caso de crianças em idade pré-escolar, os pais que trabalhavam por turnos, quando comparados com os diurnos, tinham mais tempo livre comum com os seus filhos, enquanto que no caso das crianças em idade escolar ocorre a situação inversa. Por exemplo, no período em que são realizados turnos da tarde, dependendo do horário do turno e do horário de deitar da criança, pode haver apenas entre uma a duas horas diárias em conjunto.

Os horários de trabalho por turnos, por outro lado, podem proporcionar certos benefícios neste domínio. Por exemplo, em casais de dupla carreira com crianças pequenas pode proporcionar um maior envolvimento de ambos os pais no cuidado e educação das crianças. Como refere Presser (1994), com base em Presser (1989), há certa evidência que quando ambos os pais exercem um trabalho remunerado e têm diferentes horários de trabalho, a maioria dos pais são os principais cuidadores das crianças no período em que as mães se encontram no emprego. Outro benefício relacionado com o anterior prende-se com a redução dos encargos financeiros no cuidado dos filhos. Este maior envolvimento familiar pode, no entanto, comprometer o tempo dedicado ao descanso entre turnos.

Não obstante a necessidade de estudos metodologicamente mais bem controlados (Gadbois, 2004) e que incorporem as mudanças societais mais recentes, existe um considerável grau de consenso na literatura de que o trabalho por turnos e os horários irregulares, quando comparados com o trabalho diurno fixo, podem impor exigências acrescidas na organização das actividades domésticas e familiares dada a diversidade de padrões horários que têm que ser geridos no seio do sistema familiar. 


\subsubsection{ESFERA SOCIAL}

Dada a sua experiência em horários de trabalho diferentes do horário diurno dito convencional, poder-se-ia supor que os trabalhadores por turnos, pudessem, de algum modo, "deslocar" a valoração social do tempo para outros períodos diferentes daqueles que são valorizados pelos trabalhadores diurnos. Porém, a investigação realizada (ex., Wedderburn, 1981; Hornberger \& Knauth, 1993; Baker et al., 2003) tem indicado que os trabalhadores por turnos, genericamente, exibem um padrão de valoração social do tempo muito similar aos trabalhadores diurnos. Por exemplo, Baker e colaboradores (2003) avaliaram se os trabalhadores por turnos, quando comparados com os trabalhadores diurnos, apresentavam diferenças na preferência do tempo para realizar as actividades habitualmente inscritas em quatro esferas: trabalho, família, social e lazer. Os resultados indicaram que os períodos mais valorizados por ambos os grupos para a realização de actividades inscritas nos domínios social, lazer e família se situam ao final do dia durante os dias úteis da semana e ao fim-de-semana. À excepção do "tempo social", os trabalhadores por turnos parecem, no entanto, ser mais flexíveis na utilização do tempo durante os dias úteis da semana. Essa mesma "flexibilidade" parece estar presente no tempo de trabalho, ainda que o período mais valorizado pelos trabalhadores por turnos seja exactamente o mesmo que os trabalhadores diurnos manifestaram, ou seja, de segunda a sexta-feira, durante o dia.

Outros estudos referidos por Gadbois (2004) indicam, de modo consistente, o padrão de resultados descrito anteriormente. Os resultados obtidos neste tipo de estudos ajudam pois a compreender o impacto social dos horários de trabalho que "colidem" com a estruturação temporal da sociedade. De facto, ainda que os trabalhadores por turnos possam atribuir uma valoração mais positiva ao tempo livre e familiar durante os dias úteis do que os trabalhadores diurnos, as actividades inscritas na esfera social necessitam de ocorrer, forçosamente, em paralelo com o tempo social dos outros e, nesse sentido, o valor desse tempo dificilmente será transferível entre os dias da semana. Assim, quanto mais "desviante" for o horário de trabalho da organização temporal da sociedade, mais queixas são expressas 
(Wedderburn, 2000). Neste âmbito, importa também sublinhar que a "utilidade social do tempo" dos diferentes momentos do dia ou da semana não constituem uma propriedade intrínseca, estando sempre dependente dos contextos e dos padrões sociais presentes nos diferentes países e/ou regiões (Gadbois, 2004).

Além da organização do dia-a-dia, o trabalho por turnos, nomeadamente quando envolve trabalho realizado ao sábado e ao domingo, pode interferir com os ritmos semanais das actividades de massa, como eventos desportivos, culturais ou religiosos (Wedderburn, 1981; Walker, 1985; Costa, 1997). Os horários de trabalho irregulares encontram-se também associados a muitas queixas neste domínio, dado que trazem dificuldades acrescidas quer na organização da vida diária quer no planeamento de actividades, a médio e a longo prazo (Costa, 1997).

Não obstante as dificuldades acrescidas que o trabalho por turnos pode representar na prossecução de certas actividades, também tem sido assinalado que este regime de trabalho poderá facilitar outras, nomeadamente, aquelas que estão menos dependentes da interacção social. A título de exemplo, vejamos os resultados obtidos no estudo de Wedderburn (1981). Neste estudo foram realizadas entrevistas a mais de 300 trabalhadores por turnos submetidos a sistemas contínuos de turnos rotativos da indústria do aço, dos quais 97\% eram do sexo masculino. Os aspectos em que mais trabalhadores referiram sair mais beneficiados do que prejudicados foram os seguintes: ir às compras (33\% versus 10\%), ir ao banco (39\% versus $4 \%$ ) e ir a repartições públicas (39\% versus 5\%). Por fim, os aspectos positivos associados ao sistema de turnos, em comparação com o horário diurno, foram, por ordem decrescente: remuneração (88\%), "liberdade" durante o dia (66\%), tempo para si próprio (61\%), tempo livre (57\%) e variedade nos horários de trabalho (55\%).

Alguns autores (ex., Mott et al., 1965; Walker, 1985; Gadbois, 2004) têm referido também o facto dos trabalhadores por turnos puderem ter dificuldades acrescidas em manter contactos com os amigos, sobretudo se estes não pertencem ao círculo dos colegas de trabalho. Walker (1985), refere também a menor probabilidade dos trabalhadores por turnos, em comparação com os diurnos, serem membros activos de organizações civis e/ou 
de participarem em actividades institucionais (ex., partidos políticos, associações de pais, grupos recreativos) uma vez que estas tendem a ocorrer no tempo livre acoplado ao horário de trabalho diurno fixo.

Em contraste, os passatempos ou actividades de natureza solitária (ex., jardinagem, pesca), particularmente aquelas que são realizadas durante o dia, poderão beneficiar o trabalhador por turnos face ao trabalhador diurno (Walker, 1985), podendo também o maior tempo livre ser dispendido na realização de um segundo trabalho remunerado, tipicamente, subsidiário do primeiro (Silva, 2008). Ainda que muitas das actividades de lazer possam ser realizadas durante o dia, importa, também, ressalvar eventuais implicações resultantes da sua posição cronológica no dia e na semana. Por exemplo, no estudo de Silva (1999) foi comparado um grupo de enfermeiras submetidas a um sistema contínuo de rotação rápida com um grupo de enfermeiras submetidas ao horário diurno fixo ao nível da regularidade das suas actividades diárias ao longo de duas semanas consecutivas. Por exemplo, na actividade "ver televisão", enquanto que uma maior frequência das profissionais que trabalhavam no horário rotativo viam televisão "antes do jantar" de modo regular, as que praticavam o horário diurno apresentam uma maior regularidade nessa actividade "depois do jantar", ou seja, num período em que habitualmente este comportamento é realizado na companhia da família. Neste estudo, foi também observado que para mais de metade das profissionais (60\%) sujeitas a um sistema contínuo de rotação rápida, a principal desvantagem apontada ao horário de trabalho se relacionava com o facto de este obrigar a "trabalhar à noite e aos fins-de-semana, não podendo estar com a família”, enquanto que a principal vantagem referida se relacionava o facto de proporcionar "mais tempo livre" (70\%).

Em suma, o trabalho por turnos pode ter repercussões negativas na vida familiar do trabalhador por turnos e empobrecer a sua interacção do ponto de vista social, constituindo tais dificuldades razões frequentes para o abandono desse regime horário. Porém, este modo de organização do tempo de trabalho poderá também favorecer certo tipo de actividades, como, por exemplo, as temporalmente flexíveis e de natureza solitária. Na verdade, os aspectos que envolvem a relação entre trabalho por turnos e aspectos sociais não são simples, podendo algumas consequências ser vistas como 
positivas, outras como negativas e, ambas, podem variar em função dos interesses e das circunstâncias do trabalhador e da sua família. Em todo o caso, como sublinhava Walker (1985), embora não seja possível fazer-se generalizações neste domínio, os dados disponíveis até à data indicam que as desvantagens sociais do trabalho por turnos são maiores do que as vantagens proporcionadas, observação que cremos manter relevância actual.

\subsection{CONSEQUENACIAS NO CONTEXTO LABORAL}

\subsubsection{SEGURANÇA}

Pese embora a enorme dificuldade em controlar todos os factores susceptíveis que podem concorrer para o risco de acidentes de trabalho no decurso das vinte e quatro horas, existe evidência crescente que este tende a ser maior durante o período nocturno do que noutros períodos do dia (Dinges, 1995; Folkard, 1997; Folkard \& Tucker, 2003) em vários contextos de actividade.

Por exemplo, a análise de Folkard (1997) de seis estudos indicou uma variação circadiana no risco de acidentes rodoviários em operações de transporte, atingindo este o pico entre as duas e as três da madrugada (foi também observado um segundo "pico", embora menos pronunciado, ao início da tarde), enquanto que na área da saúde, um inquérito realizado por Folkard, Condon e Herbert (1984), e citado por Felton (1987), indicou que $12 \%$ das enfermeiras submetidas a trabalho nocturno referiram ter sofrido, pelo menos uma ou duas vezes, uma "paralisia de sono" totalmente incapacitante, impedindo o exercício profissional durante alguns momentos; o pico deste fenómeno ocorria por volta das quatro horas da madrugada e a sua incidência tendia a aumentar à medida que aumentava o número de noites sucessivas de trabalho.

A revisão de Folkard e Tucker (2003) sistematiza as tendências nesta matéria na indústria tendo em conta aspectos como o risco relativo de acidentes em função dos três turnos (manhã, tarde e noite), o risco ao longo 
do turno nocturno, dos dias sucessivos em cada turno e da duração do horário de trabalho. Refira-se também que a análise do risco de acidentes foi realizada com base na estandardização dos resultados obtidos em vários estudos de campo. Quanto ao risco de acidentes nos três turnos, foi observado um aumento de risco de $18.3 \%$ no turno da tarde e de $30.4 \%$ no turno da noite face ao turno da manhã. Quanto à análise do risco ao longo do turno nocturno (tendo sido considerados turnos com uma duração de oito horas) observa-se um aumento de risco em cerca de $20 \%$ na segunda hora de trabalho nocturno face à primeira; no período subsequente, regista-se uma diminuição total de risco (aproximadamente 50\%) ao longo do período de trabalho, atingindo o valor mínimo no final do turno; não obstante essa tendência geral, regista-se um pequeno aumento no risco relativo no período compreendido entre as três e as quatro horas da manhã, ainda que esse efeito seja relativamente pequeno quando comparado com a redução substancial que ocorre a partir da segunda hora de trabalho. Relativamente ao risco relativo de acidentes ao longo de noites sucessivas de trabalho, tendo sido analisadas apenas até quatro noites em sucessão, foi observado, em relação à primeira noite de trabalho, um acréscimo de cerca de $6 \%$ na segunda noite, $17 \%$ na terceira noite e de 36\% na quarta noite. Além do turno da noite, foi também analisado o risco relativo ao longo da sucessão de turnos diurnos. Neste caso, o risco também aumenta ao longo dos três dias em sucessão, face ao primeiro dia de trabalho, mas em menor magnitude; os valores observados foram, respectivamente, cerca de 2\%, 7\% e 17\%. Quanto à duração do horário de trabalho, embora os estudos disponíveis sejam mais escassos, foi observado que o risco relativo de acidentes na décima segunda hora de trabalho era mais do dobro do que no final das oito horas de trabalho. Em suma, a revisão efectuada indica que o turno da noite é o que está associado a um maior risco relativo de acidentes, enquanto que o turno da manhã é aquele que está associado a uma menor frequência; considerando apenas o turno da noite, os resultados indicam que o risco relativo de acidentes tende a ser maior nas primeiras horas de trabalho e ao longo de noites sucessivas.

Numa perspectiva complementar, o estudo de Akerstedt, Fredlund, Gillberg e Jansson (2002) indicou uma associação entre risco de acidentes 
ocupacionais mortais e o tipo de horário de trabalho. Neste estudo foi analisado com base numa amostra nacional, em que medida um conjunto de factores (sexo, idade, grupo sócio-económico, dificuldades de sono, horário de trabalho, ritmo de trabalho e duração semanal do trabalho) constituíam factores de risco de acidentes ocupacionais mortais, tendo sido concluído ser factores de risco significativos, além da variável sexo (neste caso, ser homem), as dificuldades de sono e trabalhar num horário não diurno. Neste contexto, acrescente-se também o maior de risco de acidentes rodoviários na deslocação do local de trabalho para casa no final do turno dadas as dificuldades acrescidas em manter-se acordado (ex., Dorrian et al., 2008).

Os horários de trabalho irregulares e por turnos aumentam o risco de acidentes, aparentemente, mediados pela sonolência e a redução do desempenho a si associada dado que o nível "minimo" (i.e., nadir) do sistema circadiano está associado a uma reduzida activação fisiológica, alerta subjectivo ou eficiência comportamental (Åkerstedt, 1990, 1995).

\subsubsection{PRODUTIVIDADE}

À semelhança do que ocorre com o estudo dos determinantes temporais na segurança ocupacional, também a produtividade em contexto real pode ser influenciada por diversos factores que podem variar ao longo do dia, tornando difícil a comparação entre os diferentes momentos. É frequente, por exemplo, em contextos industriais, as operações de manutenção e os níveis de supervisão encontrarem-se reduzidos durante o período nocturno, além de poder haver variações nas condições físicas de trabalho, na natureza das tarefas executadas ou, mesmo, na composição da força de trabalho (Monk \& Folkard, 1985; Folkard, 1997; Thierry \& Jansen, 1998). No contexto dessas dificuldades, tem sido salientado (ex., Monk \& Folkard, 1985; Vidacek, Kaliterna, Radosevic-Vidacek \& Folkard, 1986; Folkard \& Tucker, 2003) o facto de poucos estudos terem obtido com sucesso medidas "incontaminadas" de desempenho em contexto real de trabalho nos diferentes turnos. No entanto, os estudos que conseguiram ultrapassar essas dificuldades, 
globalmente, têm apontado para níveis de produtividade mais baixos durante a noite (Monk \& Folkard, 1985; Folkard, 1997; Folkard \& Tucker, 2003).

Folkard e Tucker (2003) analisaram a variação de desempenho ao longo das 24 horas em três estudos de campo integrados em diferentes áreas de actividade e envolvendo vários sistemas de turnos contínuos, tendo o desempenho sido avaliado através de medidas objectivas em termos de velocidade ou de exactidão de execução. Da análise conjunta dos três casos (baseada na estandardização dos resultados), sobressaem duas tendências: i) uma diminuição/quebra relativamente pronunciada na eficiência do desempenho no decurso do turno nocturno (22h-6h), com o pico a ocorrer às três horas da madrugada; e, ii) uma segunda quebra, embora menos acentuada, no período logo a seguir ao meio-dia, efeito que é comummente designado como "quebra pós-almoço" ("post-lunch dip").

O estudo de Vidacek e colaboradores (1986) procurou controlar também um conjunto de factores susceptíveis de influenciar a produtividade no decurso das vinte e quatro horas, tendo este sido realizado numa empresa produtora de componentes eléctricos. Os resultados obtidos indicaram haver um efeito significativo entre o tipo de turno e os níveis de produtividade, tendo sido a produção média no turno da tarde a mais elevada e a mais baixa a do turno da noite. Por outro lado, o turno da noite também se diferenciou dos restantes em termos do padrão de produtividade ao longo da semana. Especificamente, os níveis de produtividade nesse turno foram substancialmente mais reduzidos na primeira e na segunda noite de trabalho (em média, respectivamente, menos 100 e 50 componentes produzidas), atingiram o pico na terceira noite, descendo, embora de modo menos acentuado, nas noites subsequentes (i.e., quarta e quinta noites). Em contraste, os níveis de produtividade nos turnos da manhã e da tarde mantiveram-se relativamente constantes ao longo da semana.

No intuito de ultrapassar muitos dos problemas inerentes aos estudos de campo (ex., variabilidade das condições de trabalho ao longo do dia), diversos autores realizaram estudos de "simulação de trabalho por turnos" em contexto laboratorial (frequentemente, com estudantes voluntários) ou estudos com "tarefas interpoladas", isto é, estudos em que os trabalhadores por turnos executam tarefas "artificiais", típicas de laboratório, habitualmente 
no seu contexto natural de trabalho (Monk \& Folkard, 1985). Os resultados obtidos no âmbito dessas abordagens confirmam, de um modo geral, a inferioridade no desempenho durante o período nocturno. Por outro lado, enfatizam a importância da acumulação dos efeitos da privação parcial de sono na compreensão da redução do desempenho, especialmente no caso de tarefas monótonas e aquelas cujo ritmo de trabalho é determinado pelo equipamento produtivo. Por fim, evidenciam também velocidades de ajustamento diferentes à inversão do ciclo sono-vigília para tarefas de natureza diferente (ex., carga cognitiva envolvida); de um modo geral, quanto maior for a complexidade das tarefas, mais rápido é o processo de ajustamento.

De um modo genérico, têm sido propostos dois processos para a compreensão da regulação da eficiência do desempenho e do alerta subjectivo - um processo homeostático (quantidade de horas desde o acordar) e um processo circadiano (relógio biológico) - presumindo-se que as flutuações observadas no desempenho ao longo do dia sejam geradas pela interacção de ambos (Carrier \& Monk, 2000). Assim, presume-se que os níveis de segurança e de produtividade estão reduzidos durante o período de trabalho nocturno devido a duas ordens de razão: i) os ritmos circadianos do desempenho exibem os valores mais baixos nesse período; ii) esses ritmos mantêm-se relativamente desajustados ao longo de noites sucessivas de trabalho (Folkard \& Tucker, 2003). Em todo o caso, deve ser reconhecido que o processo é multifacetado e de natureza interactiva (Monk \& Folkard, 1985; Folkard \& Tucker, 2003). Como referem Thierry e Jansen (1998), níveis iguais de produtividade não correspondem necessariamente a níveis iguais de esforço; a obtenção durante a noite dos mesmos padrões diurnos pode ser conseguida à custa de um esforço "extra" (ou, se quisermos, de uma "motivação extra") dado o baixo nível de activação a que o organismo pode estar sujeito.

\subsubsection{ABSENTISMO}

Dado o leque de efeitos do trabalho por turnos ao nível da saúde, poder-se-ia esperar uma maior taxa de absentismo por doença dos trabalhadores 
por turnos em comparação com os trabalhadores diurnos. No entanto, os resultados encontrados, de um modo geral, têm apontado para resultados inconsistentes. Com efeito, os resultados obtidos em diversos estudos reportados por Costa (1996), Kleiven, Boggild e Jeppesen (1999) e Wedderburn (2000) apontam para um padrão inconsistente de resultados nesta matéria. Adicionalmente observaram que factores como o tipo de sistema de turnos envolvido ou ter sido ex-trabalhador por turnos, parecem constituir factores relevantes na detecção das diferenças entre trabalhadores por turnos e trabalhadores diurnos.

No sentido de explicar a incongruência de resultados associada à comparação do absentismo por doença entre trabalhadores por turnos e trabalhadores diurnos, têm sido referidos na literatura alguns factores. Wedderburn (2000), sistematiza-os em três: i) efeito de selecção; ii) pressão social; iii) subestimação dos problemas experienciados.

O efeito de selecção, também designado como "efeito do trabalhador por turnos saudável", resulta do facto dos trabalhadores que sentem maiores dificuldades em lidar com o regime de trabalho por turnos, tenderem a abandoná-lo; esta saída pode resultar da iniciativa do próprio trabalhador ("processo de auto-selecção") e/ou de aconselhamento médico (Wedderburn, 2000); assim, tendem a permanecer no trabalho por turnos aqueles indivíduos que conseguem gerir mais eficazmente as exigências por este impostas e a sair os que mais dificuldades sentem nessa gestão. Alguns estudos (ex., Koller, 1983) que consideram na análise do absentismo por doença o grupo de ex-trabalhadores por turnos, têm encontrado uma maior taxa nestes.

Outros autores têm sugerido que os trabalhadores por turnos, especialmente quando está envolvido trabalho nocturno, podem diferir dos trabalhadores diurnos ao nível das relações intra-grupo, nomeadamente no desenvolvimento de um maior "espírito de camaradagem" ("espirit de corps") (Knauth, 1993; Kleiven et al., 1999), o qual, teria impacto no comportamento de ausência no trabalho. Dito de outro modo, os trabalhadores por turnos podem constituir um grupo mais solidário, impelindo os seus membros a não faltarem (Costa, 1996).

Por fim, outros autores têm também observado que os trabalhadores por turnos, em comparação com os trabalhadores diurnos, tendem a subestimar 
mais frequentemente os problemas que podem experienciar (ex., problemas de sono, problemas digestivos) uma vez que estes são encarados como "fazendo parte" do tipo de trabalho a que estão sujeitos (Costa, 1996, 2003; Kleiven et al., 1999; Wedderburn, 2000).

\section{CONClusão E CONSIDERAÇÕES FinAis}

Une meilleure articulation synergique entre le technique, le biologique et le social, entre les machines et les hommes, contient la promesse d'une efficacité économique que toute entreprise dans quelque pays qu'elle soit cherche à réaliser.

Brunstein e Andlauer, 1988, p. 4.

A crescente diversificação dos horários de trabalho tem sido referida como uma das mudanças mais significativas que ocorreu nas últimas décadas do ponto de vista ocupacional (Thierry \& Jansen, 1998; Härmä \& Ilmarinen, 1999; Peiró, Prieto \& Roe, 2002), estando subjacente a esta, como vimos, factores de natureza económica, tecnológica e sócio-cultural. No que ao horário de trabalho por turnos diz respeito, vimos que este permite às organizações a extensão do seu período de laboração, prolongamento que pode revelar-se imprescindível do ponto de vista social (ex., assegurar serviços públicos 24 horas por dia) ou do ponto de vista técnico (ex., impossibilidade de suster processos de fabrico). Tal prolongamento pode, no entanto, representar uma estratégia organizacional cujo interesse exclusivo é de natureza económica (ex., aumentar a capacidade produtiva e/ou rentabilizar o equipamento produtivo).

O crescente envelhecimento da população activa nos países industrializados em conjunto com os recentes dados epidemiológicos relativos à relação entre trabalho por turnos e fadiga, desempenho e efeitos crónicos na saúde, levam Härmä e Ilmarinen (1999) a referir que existem razões para acreditar que o trabalho por turnos possa constituir, num futuro próximo, um dos principais problemas do ponto de vista da saúde e da segurança ocupacionais. Por outro lado, certas mudanças societais em curso como o crescente 
número de casais de dupla carreira ou de famílias mono-parentais colocam igualmente questões relevantes no modo como o tempo de trabalho é organizado, em especial ao nível da interface trabalho-família (Fagan, 2001a). Da parte da comunidade científica também é possível constatar um crescente interesse na compreensão dos efeitos associados à organização do tempo de trabalho, incluindo a organização do tempo de trabalho por turnos.

A revisão efectuada ao longo do presente capítulo indica que as perturbações associadas ao horário de trabalho por turnos são várias e de natureza multifacetada, envolvendo questões de saúde, aspectos ocupacionais e dinâmicas familiares e sociais. Do ponto de vista social, a "colisão" entre determinados horários de trabalho e as outras esferas da vida, grande parte delas estruturadas colectivamente, constitui a dificuldade mais visível. Por outro lado, as principais vantagens associadas a este regime horário, além da compensação financeira, situam-se também ao nível da dimensão mais social. Do ponto de vista da saúde e do contexto ocupacional (segurança e desempenho), o principal problema parece residir no conflito entre a orientação diurna do sistema circadiano humano e os padrões de sono e de vigilância exigidos pelo horário de trabalho nocturno, fixo ou alternado. Neste âmbito, o turno da manhã com início muito cedo tem sido, igualmente, associado a alguns dos problemas descritos. Enquanto que algumas das perturbações se podem manifestar a curto prazo (ex., sonolência, fadiga, conflitos familiares), deve ser salientado que outras (ex., doenças cardiovasculares), o risco, eventualmente, só se materializará após longos períodos de exposição ao regime de trabalho que envolva trabalho nocturno.

A revisão de literatura efectuada sugere também que o interesse no estudo dos efeitos do trabalho por turnos tem de algum modo privilegiado o impacto ao nível na saúde dos trabalhadores. Não obstante a relevância destes efeitos quer em termos de incidência quer em termos da necessidade de continuidade de esforços de investigação, sobretudo ao nível dos mecanismos etiopatológicos envolvidos, a literatura neste domínio tem igualmente salientado a necessidade de maiores esforços de investigação nos problemas inseridos nas esferas familiar e social, principalmente, do ponto de vista do desenvolvimento conceptual. Com efeito, diversos autores, ao longo das últimas décadas (ex., Mott et al., 1965; Walker, 1985; Brunstein \& Andlaeur, 
1988; Wedderburn, 2000; Gadbois, 2004), têm sublinhado que as investigações nestes domínios, quando comparadas com os aspectos médicos e fisiológicos do trabalho por turnos, se caracterizam por um menor número e por um carácter menos específico. Algumas razões têm sido, no entanto, avançadas para ajudar a compreeder esta discrepância, nomeadamente: i) enquanto que a investigação dos aspectos biológicos do trabalho por turnos tem sido moldada sob o quadro teórico da cronobiologia, a investigação dos aspectos sociais, de um modo geral, não tem sido assente em qualquer background teórico (Walker, 1985); ii) menor participação de investigadores das áreas sociais, como psicólogos sociais ou sociólogos na compreensão da problemática do trabalho por turnos (Mott et al., 1965; Gadbois, 2004); iii) o estudo da interface trabalho-família, mesmo quando abordada por profissionais da área do comportamento organizacional, raramente segue os seus sujeitos para além das fronteiras organizacionais (Barton et al., 1998), sendo raros os estudos que examinem o impacto indirecto do trabalho por turnos nos membros do sistema familiar e sua relação com os efeitos experienciados pelos trabalhadores por turnos (Barton et al., 1998; Gadbois, 2004); iv) o elevado grau de complexidade da vida social, tornando difícil a sua operacionalização e consequente estudo (Gadbois, 2004). Da nossa parte, esperamos que o presente trabalho possa de algum modo contribuir para despoletar o interesse por esta problemática por parte dos profissionais que estudam e intervêm nas organizações em geral e dos(as) psicólogos(as) do trabalho e das organizações em particular. No nosso entender, este interesse torna-se ainda mais relevante se atendermos que os factores do contexto organizacional se têm revelado promissores na compreensão e na gestão desta problemática como referido brevemente na parte final deste último ponto.

Refira-se também que os vários efeitos descritos ao longo deste capítulo poderão ser minimizados ou exacerbados em função de um conjunto bastante assinalável de factores, podendo estes, de um modo global, serem agrupados em dois grandes domínios: factores de natureza individual e factores de natureza situacional ou contextual (ex., Härmä, 1993; Nachreiner, 1998; Smith et al., 2003). No caso dos factores individuais, os mais estudados têm sido os relativos à idade, sexo, características da personalidade (ex., 
introversão/extroversão), amplitude dos ritmos circadianos e características do cronótipo (ex., tipo circadiano, tipo diurno). Quanto aos factores de natureza situacional, estes podem ainda ser divididos em factores do contexto familiar e social (ex., características da estrutura familiar, atitude do(a) companheiro(a) face ao regime de turnos, apoio social dos familiares e dos amigos mais próximos, estruturas sociais dosponíveis) e do contexto organizacional.

No caso dos factores do contexto organizacional susceptíveis de influenciar a adaptação ao trabalho por turnos (e que naturalmente têm implicações ao nível da intervenção), sobressaem as características do sistema de turnos e o apoio proporcionado pela organização, traduzido este, entre outros aspectos, nas práticas adoptadas em termos de gestão do tempo de trabalho. Os méritos relativos dos diferentes tipos de sistemas de turnos constituem provavelmente o tópico mais debatido no âmbito da problemática do trabalho por turnos (Smith et al., 2003), tendo a intervenção neste domínio sido assinalada (ex., Barton \& Folkard, 1933; Knauth, 1996; Silva, 2000; Amelsvoort, Jansen, Swaen, van den Brandt \& Kant, 2004) como uma das estratégias mais efectivas para reduzir os problemas que os trabalhadores poderão experienciar. Neste âmbito têm sido estudados fundamentalmente três aspectos dos sistemas de turnos: velocidade de rotação, sentido de rotação e, mais recentemente, duração dos turnos, envolvendo tal aspecto tipicamente a comparação entre turnos de 8 e de 12 horas.

A par do suporte da família, o suporte social recebido no contexto laboral, nomeadamente das chefias e dos colegas de trabalho, tem-se mostrado recentemente relevante na compreensão da tolerância ao trabalho por turnos (Nachreiner, 1998). Com efeito, alguns estudos realizados em contexto hospitalar com estudantes de enfermagem a iniciar a experiência de trabalho por turnos (Bohle \& Tilley, 1989, 1993) ou com profissionais na área da saúde (Pisarski, Bohle \& Callan, 1998, 2002) têm apontado nesse sentido. Por exemplo, no estudo de Pisarski e colaboradores (1998), com profissionais de enfermagem submetidas a turnos rotativos, o suporte social da família e do contexto ocupacional (colegas e supervisores) revelou ter efeitos quer directos quer indirectos no conflito trabalho/não trabalho e na saúde psicológica. Especificamente, o suporte social dos colegas teve efeitos directos 
na saúde psicológica, enquanto que os efeitos do suporte das chefias na saúde psicológica foi mediado pelo suporte dos colegas. Foi também observado que o efeito do suporte social da chefia no conflito trabalho/não trabalho foi mediado pelo controlo que os trabalhadores por turnos poderiam exercer nas suas afectações aos turnos. O estudo de Pisarski e colaboradores (2002), observou igualmente uma associação entre o suporte social da chefia e o grau de controlo dos turnos e, entre este, e o conflito trabalho/não trabalho.

Mais recentemente, o estudo de Pisarski, Lawrence, Bohle \& Brook (2008) com profissionais de enfermagem, acrescenta aos factores do contexto organizacional anteriores, a influência da identidade e do clima da equipa de trabalho na redução do conflito trabalho-família e nos problemas de saúde. Num dos estudos realizados por Silva (2008) com operários têxteis foi também observado que o suporte do contexto organizacional influenciava de modo significativo a satisfação com a interface entre o horário de trabalho e a vida extra-organizacional e, que esta, era o factor que mais influenciava a avaliação do horário de trabalho.

Outros estudos (ex., Krausz, Sagie \& Bidermann, 2000; Fenwick \& Tausig, 2001) têm reforçado a relevância da variável controlo individual sobre o tempo de trabalho. Por exemplo, Fenwick e Tausig (2001) analisaram os efeitos de diferentes tipos de arranjos horários de trabalho (ex., turno diurno fixo, turno não diurno fixo de segunda a sexta-feira, horários rotativos) e da percepção de controlo do tempo de trabalho em vários indicadores na saúde e na vida familiar com base nos dados de um inquérito nacional norte-americano. Globalmente, verificaram que os trabalhadores com maiores níveis de controlo do tempo de trabalho reportavam de modo significativo menos problemas em ambos os domínios.

Em termos práticos, o conjunto dos dados anteriores sugere que o contexto organizacional poderá desempenhar um papel relevante na redução do conflito trabalho/não trabalho e nos efeitos negativos na saúde, nomeadamente, através do ambiente social criado e da possibilidade dada ao trabalhador de poder exercer algum grau de participação (ou, se quisermos, de controlo) sobre o seu tempo de trabalho, sendo que essa participação pode manifestar-se sob várias circunstâncias como no desenho do próprio sistema de turnos, 
na escolha em trabalhar num horário de trabalho particular ou na influência que pode exercer na afectação às escalas de turnos que são trabalhadas. Por outro lado, as práticas organizacionais sensíveis às preferências e às necessidades dos trabalhadores poderão também mais facilmente "acomodar" diferenças individuais de natureza biológica (ex., "matutinidade-vespertinidade", avanço de fase com o aumento da idade) que se possam revelar importantes na adaptação a certos tipos de horários de trabalho, donde se destaca aqueles que envolvem noites ou que se iniciam muito cedo.

\section{BIBLIOGRAFIA}

Åkerstedt, T. (1985). Adjustment of physiological circadian rhythms and the sleep-wake cycle to shiftwork. In S. Folkard \& T. H. Monk (Eds.), Hours of work: Temporal factors in work-scheduling (pp. 185-197). Chichester: John Wiley \& Sons Ltd.

Åkerstedt, T. (1990). Psychological and psychophysiological effects of shift work. Scandinavian Journal of Work and Environmental Health, 16(Suppl. 1), 67-73.

Åkerstedt, T. (1995). Work hours, sleepiness and the underlying mechanisms. Journal of Sleep Research, 4(Suppl. 2), 15-22.

Åkerstedt, T. (2003). Shift work and disturbed sleep/wakefulness. Occupational Medicine, 53, 89-94.

Åkerstedt, T., Fredlund, P., Gillberg, M., \& Jansson, B. (2002). A prospective study of fatal occupational accidents - relationship to sleeping difficulties and occupational factors. Journal of Sleep Research, 11, 69-71.

Åkerstedt, T., \& Gillberg, M. (1981). Sleep disturbances and shift work. In A. Reinberg, N. Vieux \& P. Andlauer (Eds.), Night and shift work: Biological and social aspects (pp. 127-137). Oxford: Pergamon Press.

Åkerstedt, T., \& Torsvall, L. (1985). Napping in shift work. Sleep, 8(2), 105-109.

Allan, C., Brosman, P., \& Walsh, P. (1998). Non-standard working-time arrangements in Australia and New Zeland. International Journal of Manpower, 19(4), 234-149.

Amelsvoort, L., Jansen, N., Swaen, G., van den Brandt, P., \& Kant, J. (2004). Direction of shift rotation among three-shift workers in relation to psychological health and work-family conflict. Scandinavian Journal of Work and Environmental Health, 30(2), 149-156.

Armstrong, L. (2000). Performing in extreme environments. Champaign III: Human Kinetics.

Aschoff, A. \& Wever, R. (1992). The circadian system of man. In J. Aschoff (Ed.), Handbook of behavioural neurobiology, biological rhythms (Vol. 4, Biological rhythms) (3rd ed., pp. 311-331). New York and London: Plenum Press.

Ashkenazi, I. E., Reinberg, A. E., \& Motohashi, Y. (1997). Interindividual differences in the flexibility of human temporal organization: Pertinence to jet lag and shiftwork. Chronobiology International, 14(2), 99-113.

Baker, A., Ferguson, S., \& Dawson, D. (2003). The perceived value of time: Controls versus shiftworkers. Time \& Society, 12(1), 27-39. 
Baltes, B. B., Briggs, T. E., Huff, J. W., Wright, J. A., \& Neuman, G. A. (1999). Flexible and compressed workweek schedules: A meta-analysis of their effects on work-related criteria. Journal of Applied Psychology, 84(4), 496-513.

Barton, J., Aldridge, J., \& Smith, P. (1998). The emotional impact of shift work on the children of shift workers. Scandinavian Journal of Work and Environmental Health, 24(Suppl. 3), 146-150.

Barton, J., \& Folkard, S. (1993). Advancing versus delaying shift systems. Ergonomics, 36(1-3), 59-64.

Barton, J., Spelten, E., Totterdell, P., Smith, L., Folkard, S., \& Costa, G. (1995). The Standard Shiftwork Index: A battery of questionnaires for assessing shiftwork-related problems. Work \& Stress, 9(1), 4-30.

Beers, T. M. (2000). Flexible schedules and shift work: Replacing the '9-to-5' workday? Montbly Labor Review, 123(6), 33-40.

Blyton, P., Hassard, J., Hill, S., \& Starkey, K. (1992). Time, work and organization (2 ${ }^{\text {nd }}$ ed.). New York: Routledge.

Boggild, H., \& Knutsson, A. (1999). Shift work, risk factors and cardiovascular disease. Scandinavian Journal of Work and Environmental Health, 25 (2), 85-99.

Boggild, H, Burr, H., Tüchsen, F., \& Jeppesen, H. J. (2001). Work environment of Danish shift and day workers. Scandinavian Journal of Work and Environmental Health, 27(2), 97-105.

Bohle, P., \& Tilley, A. (1989). The impact of night work on psychological well-being. Ergonomics, 32(9), 1089-1099.

Bohle, P., \& Tilley, A. (1993). Predicting mood change on nigh shift. Ergonomics, 36(1-3), 125-133.

Boisard, P., Cartron, D., Gollac, M., \& Valeyre, A. (2003). Time and work: Duration of work. Ireland: European Foundation for the Improvement of Living and Working Conditions.

Boulin, J. (1993). The social organization of time. Futures, 25(5), 511-520.

Brunstein, I., \& Andlauer, P. (1988). Le travail posté: Chez nous et ailleurs. Marseille: Les Editions Octarès/Entreprises.

Carrier, J., \& Monk, T. H. (2000). Circadian rhythms of performance: New trends. Chronobiology International, 17(6), 719-735.

Cole, R. J., Loving, R. T., \& Kripke, D. F. (1990). Psychiatric aspects of shiftwork. Occupational Medicine: State of the Art Reviews, 5(2), 301-314.

Comperatore, C. A., \& Krueger, G. P. (1990). Circadian rhythm desynchronosis, jet lag, shift lag, and coping strategies. Occupational Medicine: State of the Art Reviews, 5(2), 323-341.

Costa, G. (1996). The impact of shift and night work on health. Applied Ergonomics, 27(1), 9-16.

Costa, G. (1997). The problem: Shiftwork. Chronobiology International, 14(2), 89-98.

Costa, G. (2003). Shift work and occupational medicine: An overview. Occupational Medicine, 53, 83-88.

Costa, G., Apostoli, P., d'Andrea, F., \& Gaffuri, E. (1981). Gastrointestinal and neurotic disorders in textile shift workers. In A. Reinberg, N. Vieux \& P. Andlauer (Eds.), Night and shift work: Biological and social aspects (pp. 215-221). Oxford: Pergamon Press.

Davis, S., \& Mirick, D. K. (2006). Circadian disruption, shiftwork and the risk of cancer: A summary of the evidence and studies in Seattle. Cancer Causes Control, 17, 539-545.

Demerouti, E., Geurts, S. A., \& Bakker, A. B. (2004). The impact of shiftwork on work-home conflict, job attitudes and health. Ergonomics, 47(9), 987-1002.

Di Milia, L., Bohle, P., Loundon, R., \& Pisarski, A. (2008). Editorial: Contemporary research findings in shiftwork. Applied Ergonomics, 39, 539-540.

Dinges, D. F. (1995). An overview of sleepiness and accidents. Journal of Sleep Research, 4(Suppl. 2), 4-14. 
Dorrian, J., Tolley, C., Lamond, N., van den Heuvel, C., Pincomble, J., Rogers, A., \& Drew, D. (2008). Sleep and errors in a group of Australian hospital nurses at work and during the commute. Applied Ergonomics, 39, 605-613.

Duffy, J. F., \& Dijk, D. (2002). Getting through to circadian oscillators: Why use constant routines? Journal of Biological Rhythms, 17(1), 4-13.

Fagan, C. (2001a). The temporal reorganization of employment and the household rhythm of work schedules. American Behavioral Scientist, 44(7), 1199-1212.

Fagan, C. (2001b). Time, money and the gender order: Work orientations and working-time preferences in Britain. Gender, Work and Organization, 8(3), 239-266.

Fagan, C. (2002). How many hours? Work-time regimes and preferences in European Countries. In G., Crow \& S. Heath (Eds.), Social conceptions of time - Structure and process in work and everyday life. Palgrave: Macmillar.

Fagan, C., Warren, T., \& McAllister, I. (2001). Gender, employment and working-time preferences in Europe. Luxembourg: Office for Official Publications for the European Communities.

Felton, G. (1987). Human biologic rhythms. Annual Review of Nursing Research, 5, 45-77.

Fenwick, R., \& Tausig, M. (2001). Scheduling stress - Family and health outcomes of shift work and schedule control. American Behavioral Scientist, 44(7), 1179-1198.

Folkard, S. (1992). Is there a 'best compromise' shift system? Ergonomics, 35(12), 1453-1463.

Folkard, S. (1997). Black times: Temporal determinants of transport safety. Accidents Analysis and Prevention, 29(4), 417-430.

Folkard, S., \& Barton, J. (1993). Does the 'forbidden zone' for sleep onset influence morning shift sleep duration? Ergonomics, 36(1-3), 85-91.

Folkard, S., Minors, D. S., \& Waterhouse, J. M. (1985). Chronobiology and shift work: Current issues and trends. Chronobiologia, 12(31), 31-54.

Folkard, S., \& Tucker, P. (2003). Shift work, safety and productivity. Occupational Medicine, 53, 95-101.

Gadbois, C. (2004). Les discordances psychosociales des horaires postés: Questions en suspens. Travail Humain, 67(1), 63-85.

Golembiewski, R.T., \& Proehl, C.W. (1978). A survey of the empirical literature on flexible workhours: Character and consequences of a major innovation. The Academy of Management Review, 3(4), 837-853.

Gracia, F., Peiró, J. M., \& Ramos, J. (2002). Aspectos temporales del trabajo. In J. M. Peiró \& F. Prieto (Eds.), Tratado de Psicología del trabajo: La actividad laboral en su contexto (Vol. I) (pp. 125-168). Madrid: Editorial Síntesis, S.A..

Hansen, J. (2001). Light at night, shiftwork, breast cancer risk. Journal of the National Cancer Institute, 93(20), 1513-1515.

Härmä, M. (1993). Individual differences in tolerance to shiftwork: A review. Ergonomics, 36(1-3), 101-109.

Härmä, M., \& Ilmarinen, J. E. (1999). Towards the 24-hour society - new approaches for aging shift workers? Scandinavian Journal of Work and Environmental Health, 25(6, special issue), 610-615.

Hewitt, P. (1993). About time: The revolution in work and family life. London: Rivers Oram Press.

Hornberger, S., \& Knauth, P. (1993). Interindividual differences in the subjective valuation of leisure time utility. Ergonomics, 36(1-3), 255-264.

Karlsson, B., Knutsson, A., \& Lindahl, B. (2001). Is there an association between shift work and having a metabolic syndrome? Results from a population based study of 27485 people. Environmental Medicine, 58, 747-752. 
Kecklund, G., Åkerstedt, T., \& Lowden, A. (1997). Morning work: Effects of early rising on sleep and alertness. Sleep, 20(3), 215-223.

Kivimäki, M., Kuisma, P., Virtanen, M., \& Elovainio, M. (2001). Does shift work lead to poorer health habits? A comparison between women who had always done shift work with those who had never done shift work. Work E Stress, 15(1), 3-13.

Kleiven, M., Boggild, H., \& Jeppesen, H.J. (1998). Shift work and sick leave. Scandinavian Journal of Work and Environmental Health, 24(Suppl. 3), 128-133.

Knauth, P. (1993). The design of shift systems. Ergonomics, 36(1-3), 15-28.

Knauth, P. (1996). Designing better shift systems. Applied Ergonomics, 27(1), 39-44.

Knauth, P. (1998). Innovative worktime arrangements. Scandinavian Journal of Work and Environmental Health, 24(Suppl. 3), 13-17.

Knauth, P., \& Rutenfranz, J. (1981). Duration of sleep related to the type of shift work. In A. Reinberg, N. Vieux \& P. Andlauer (Eds.), Night and shift work: Biological and social aspects (pp. 161-168). Oxford: Pergamon Press.

Knutsson, A. (2003). Health disorders of shift workers. Occupational Medicine, 53, 103-108.

Knutsson, A. (2004). Methodological aspects of shift-work research. Chronobiology International, 21(6), 1037-1047.

Knutsson, A., Åkerstedt, T., Jonsson, B. G., \& Orth-Gomer, K. (1986). Increased risk of ischemic heart disease in shift workers. Lancet, 2, 89-92.

Kogi, K. (1985). Introduction to the problems of shiftwork. In S. Folkard \& T.H. Monk (Eds.), Hours of work: Temporal factors in work-scheduling (pp. 165-184). Chichester: John Wiley \& Sons Ltd.

Koller, M. (1983). Health risks related to shift work. International Archives of Occupational and Environmental Health, 53, 59-75.

Koller, M., Haider, M., Kundi, M., Cervinka, R., Hatschnig, H., \& Kufferle, B. (1981). Possible relations of irregular working hours to psychiatric psychosomatic disorders. In A. Reinberg, N. Vieux \& P. Andlauer (Eds.), Night and shift work: Biological and social aspects (pp. 465-472). Oxford: Pergamon Press.

Krausz, M., Sagie, A., \& Bidermann, Y. (2000). Actual and preferred work schedules and scheduling control as determinants of job-related attitudes. Journal of Vocational Behavior, 56, 1-11.

Labyak, S., Lava, S., Turek, F., \& Zee, P. (2002). Effects of shiftwork on sleep and menstrual function in nurses. Health Care for Women International, 23, 703-714.

Lavie, P. (2001). Sleep-wake as a biological rhythm. Annual Review of Psychology, 52, 277-303.

Megdal, S. P., Kroenke, C. H., Laden, F., Pukkala, E., \& Schernhammer, E. S. (2005). Night work and breast cancer risk: A systematic review and meta-analysis. European Journal of Cancer, 41, 2023-2032.

Menna-Barreto, L., \& Marques, N. (2000). Datação da crise da incorporação do tempo na biologia. Psicologia: Teoria, Investigação e Prática, 5(2), 247-252.

Minors, D. S., \& Waterhouse, J. M. (1981). Circadian rhythms and the human. Bristol: John Wright \& Sons.

Minors, D. S., \& Waterhouse, J. M. (1985). Introduction to circadian rhythms. In S. Folkard \& T. H. Monk (Eds.), Hours of work: Temporal factors in work-scheduling (pp. 1-14). Chichester: John Wiley \& Sons Ltd.

Monk, T. H., \& Folkard, S. (1985). Shiftwork and performance. In S. Folkard \& T. H. Monk (Eds.), Hours of work: Temporal factors in work-scheduling (pp. 239-252). Chichester: John Wiley \& Sons Ltd.

Monk, T. H., \& Folkard, S. (1992). Making shiftwork tolerable. London: Taylor e Francis. 
Moore, R. Y. (1997). Circadian rhythms: Basic neurobiology and clinical applications. Annual Review of Medicine, 48, 253-266.

Moore-Ede, M. C., \& Sulzman, F. M. (1992). Internal temporal order. In J. Aschoff (Ed.), Handbook of behavioral neurobiology (Vol. 4, Biological rhythms) (3 $3^{\text {rd }}$ ed., pp. 215-241). New York: Plenum Press.

Moser, M., Schaumberger, K., Schernhammer, E., \& Stevens, R. G. (2006). Cancer and rhythm. Cancer Causes Control, 17(editorial), 483-487.

Mott, P. M., Mann, F. C., McLoughlin, Q., \& Warwick, D. P. (1965). Shift work: The social, psychological and physical consequences. Ann Arbor, Michigan: The University of Michigan Press.

Mozurkewich, E. L., Luke, B., Avni, M., \& Wolf, F. M. (2000). Working conditions and adverse pregnancy outcome: A meta-analysis. Obstetrics and Gynecology, 95, 623-635.

Nachreiner, F. (1998). Individual and situational determinants of shiftwork tolerance. Scandinavian Journal of Work and Environmental Health, 24(Suppl. 3), 35-42.

Nurminen, T. (1998). Shift work and reproductive health. Scandinavian Journal of Work and Environmental Health, 24(Suppl. 3), 28-34.

Ohayon, M. M., Lemoine, P., Arnaud-Briant, V., \& Dreyfus, M. (2002). Prevalence and consequences of sleep disorders in a shift worker population. Journal of Psychosomatic Research, 53, 577-583.

Parent-Thirion, A., Macías, F., Hurley, J., \& Vermeylen, G. (2007). Fourth European Working Conditions Survey. Luxembourg: Office for Official Publications of the European Communities.

Parkes, K. R. (1999). Shiftwork, job type and the work environment as joint predictors of health-related outcomes. Journal of Occupational Health Psychology, 4(3), 256-268.

Parkes, K. R. (2002). Age, smoking, and negative affectivity as predictors of sleep patterns among shiftworkers in two environments. Journal of Occupational Health Psychology, 7(2), 156-173.

Peiró, J. M., Prieto, F., \& Roe, R. A. (2002). La aproximación psicológica al trabajo en un entorno laboral cambiante. In J. M. Peiró \& F. Prieto (Eds.), Tratado de Psicología del trabajo: La actividad laboral en su contexto (Vol. I) (pp. 15-36). Madrid: Editorial Síntesis, S.A..

Peter, R., Alfredsson, L., Knutsson, A., Siegrist, J., \& Westerholm, P. (1999). Does a stressful psychosocial work environment mediate the effects of shift work on cardiovascular risk factors? Scandinavian Journal of Work Environmental Health, 25(4), 376-381.

Peter, R., \& Siegrist, J. (1999). Chronic psychosocial stress at work and cardiovascular disease: The role of effort-reward imbalance. International Journal of Law and Psychiatry, 22 (5-6), 441-449.

Pilcher, J. J., Lambert, B. J., \& Huffcutt, A. I. (2000). Differential effects of permanent and rotating shifts on self-report sleep length: A meta-analytic review. Sleep, 23(2), 155-163.

Pisarski, A., Bohle, P., \& Callan, V. J. (1998). Effects of coping strategies, social support and work-nonwork conflict on shift worker's health. Scandinavian Journal of Work and Environmental Health, 24(Suppl. 3), 141-145.

Pisarski, A., Bohle, P., \& Callan, V. J. (2002). Extended shifts in ambulance work: Influences on health. Stress and Health, 18, 119-126.

Pisarski, A., Lawrence, S. A., Bohle, P., \& Brook, C. (2008). Organizational influences on the work life conflict and health of shiftworkers. Applied Ergonomics, 39, 580-588.

Presser, H. B. (1994). Employment schedules among dual-earner spouses and the division of household labor by gender. American Sociological Review, 59, 348-364.

Presser, H. B. (2000). Nonstandard work schedules and marital instability. Journal of Marriage and the Family, 62 (February), 93-110. 
Raltson, D. A. (1989). The benefits of flextime: Real or imagined? Journal of Organizational Behavior, 10(4), 369-373.

Raltson, D. A., Anthony, W. P., \& Gustafson, D. J. (1985). Employees may love flextime, but what does it do the organization's productivity?. Journal of Applied Psychology, 70(2), 272-279.

Ruggiero, J. S. (2003). Correlates of fatigue in critical care nurses. Research in Nursing E Health, 26, 434-444.

Schabracq, M. J., \& Cooper, C. L. (2000). The changing nature of work and stress. Journal of Managerial Psychology, 15(3), 227-241.

Scherrer, J. (1981). Man's work and circadian rhythm through the ages. In A. Reinberg, N. Vieux \& P. Andlauer (Eds.), Night and shift work: Biological and social aspects (pp. 1-10). Oxford: Pergamon Press.

Silva, C. F. (2000). Distúrbios do sono do trabalbo por turnos: Factores psicológicos e cronobiológicos. Braga: Centro de Estudos em Educação e Psicologia da Universidade do Minho.

Silva, C. F., Pereira, A., Matos, P., Silvério, J., Parente, S., Domingos, M., et al. (1996). Introdução às Cronociências. Coimbra: FORMASAU - Formação e Saúde, Lda.

Silva, I. S. (1999). Trabalho por turnos: Efeitos nos estados de humor, ritmicidade biológica e social. Dissertação de Mestrado em Psicologia Clínica, Universidade do Minho, Braga.

Silva, I. S. (2000). Sistemas de turnos: Que contributos da cronopsicolobiologia para a sua concepção? Psicologia: Teoria, Investigação e Prática, 5(2), 389-410.

Silva, I. S. (2008). Adaptação ao trabalho por turnos. Dissertação de Doutoramento em Psicologia do Trabalho e das Organizações, Universidade do Minho, Braga.

Smith, C. S., Folkard, S., \& Fuller, J. A. (2003). Shiftwork and working hours. In J. C. Quick \& L. E. Tetrick (Eds.), Handbook of occupational health psychology (2nd ed.) (pp. 163-183). Washington, DC: American Psychological Association.

Staines, G. L., \& Pleck, J. H. (1984). Nonstandard work schedules and family life. Journal of Applied Psychology, 69(3), 515-523.

Tepas, D. (1985). Flexitime, compressed workweeks and other alternative work schedules. In S. Folkard \& T. H. Monk (Eds.), Hours of work: Temporal factors in work-scheduling (pp. 147-164). Chichester: John Wiley \& Sons Ltd.

Thierry, H., \& Jansen, B. (1998). Work time and behaviour at work. In P. J. D. Drenth, H. Thierry \& C. J. de Wolff (Eds.), Handbook of work and organizational psychology (Vol. 2: Work Psychology) (2nd ed., pp. 89-119). East Sussex: Psychology Press.

Totterdell, P. (2005). Work schedules. In J. Barling, E. K. Kelloway \& M. R. Frone (Eds.), Handbook of work stress (pp. 35-62). Thousand Oaks: Sage Publications.

van Amelsvoort, L. G., \& Kok, F. J. (1999). Duration of shiftwork related to body mass index and waist to hip ratio. International Journal of Obesity, 23, 973-978.

Vidacek, S., Kaliterna, L., Radosevic-Vidacek, B., \& Folkard, S. (1986). Productivity on a weekly rotating shift system: Circadian adjustment and sleep deprivation effects. Ergonomics, 12, 1583-1590.

Virtanen, S. V., \& Notkola, V. (2002). Socioeconomic inequalities in cardiovascular mortality and the role of work: A register study of Finnish men. International Journal of Epidemiology, 31, 614-621.

Volger, A., Ernst, G., Nachreiner, F., \& Hänecke, K. (1988). Common free time of family members under different shift systems. Applied Ergonomics, 19(3), 213-218.

Walker, J. (1985). Social problems of shiftwork. In S. Folkard \& T. Monk (Eds.), Hours of work: Temporal factors in work-scheduling (pp. 211-225). Chichester: John Wiley \& Sons Ltd. 
Wedderburn, A. (1981). Is there a pattern in the value of time off work? In A. Reinberg, N. Vieux \& P. Andlauer (Eds.), Night and shift work: Biological and social aspects (pp. 495-504). Oxford: Pergamon Press. Struggling

Wedderburn, A. (1998) (Ed.). Continuous shift systems. Bulletin of European Studies on Time $\left(n^{\circ}\right.$ 11). Dublin: European Foundation for the Improvement of Living and Working Conditions.

Wedderburn, A. (2000) (Ed.). Shiftwork and health. European Studies on Time. Dublin: European Foundation for the Improvement of Living and Working Conditions.

Wever, R. A. (1985). Man in temporal isolation: Basic principles of the circadian system. In S. Folkard \& T. H. Monk (Eds.), Hours of work: Temporal factors in work-scheduling (pp. 15-28). Chichester: John Wiley \& Sons Ltd.

White, L., \& Keith, B. (1990). The effect of shift work on the quality and stability of marital relations. Journal of Marriage and the Family, 52 (May), 453-462.

Zedeck, S., Jackson, S., \& Summers, E. (1983). Shift work schedules and their relationship to health, adaptation, satisfaction and turnover intention. The Academy Management Journal, 26(2), 297-310. 